\title{
SOLEIL a New Powerful Tool for Materials Science
}

\author{
F. Baudelet ', R. Belkhou 1, 2, V. Briois ${ }^{1}$, A. Coati 1, 2, P. Dumas' ${ }^{1}$, V.H. Etgens ${ }^{3}$, A.M. Flank', 2 , \\ P. Fontaine 1, 2, Y. Garreau ', 2, O. Lyon' ', I. Quinkal' , F. Rochet ${ }^{4}$, P. Roy' , M. Sauvage ', F. Sirotti ', \\ A. Somogyi ${ }^{1}$ and D. Thiaudière ${ }^{1}$
}

1 Synchrotron SOLEIL, L'Orme des Merisiers, Saint-Aubin, BP 48, 91192 Gif-sur-Yvette Cedex - France 2 LURE, Bât 209D Centre Universitaire, BP 34, 91898 Orsay Cedex - France

3 Institut des NanoSciences de Paris, Université Paris 6 et 7 Campus Boucicaut, 140, rue de Lourmel, 75015 Paris - France

4 Laboratoire de Chimie Physique - Matière et Rayonnement, 11, Rue Pierre et Marie Curie, 75231 Paris Cedex 05 - France e-mail: francois.baudeleł@synchrotron-soleil.fr - rachid.belkhou@synchrotron-soleil.fr - valerie.briois@synchrotron-soleil.fr alessandro.coati@synchrotron-soleil.fr - paul.dumas@synchrotron-soleil.fr - victor.etgens@insp.jussieu.fr anne-marie.flank@psi.ch - yves.garreau@synchrotron-soleil.fr - olivier.lyon@synchrotron-soleil.fr Isabelle.quinkal@synchrotron-soleil.fr - roch@ccr.jussieu.fr - pascale.roy@synchrotron-soleil.fr michele.sauvage@synchrotron-soleil.fr - fausto.sirotti@synchrotron-soleil.fr - andrea.somogyi@synchrotron-soleil.fr dominique.thiaudiere@synchrotron-soleil.fr

\begin{abstract}
Résumé - SOLEIL, un nouvel outil puissant pour les sciences des matériaux - À l'aube des premiers photons disponibles sur l'anneau synchrotron de troisième génération SOLEIL, un état des possibilités offertes en sciences des matériaux sera présenté. La brillance exceptionnelle de cette machine permettra de réduire de plusieurs ordres de grandeur les temps d'acquisition typiques des différentes techniques synchrotrons (spectroscopie d'absorption- EXAFS, diffusion X aux petits et grands anglesSAXS et WAXS, diffraction des rayons X -XRD, spectroscopies et microscopie de photoélectrons -XPS et PEEM, etc.) les transformant en véritables techniques operando pour la caractérisation des matériaux et plus particulièrement des catalyseurs. La résolution spatiale à l'échelle de quelques microns et même submicronique, accessible par microdiffraction et microspectroscopie dans un domaine s'étendant de l'IR lointain aux $\mathrm{X}$ durs, pourra être mise à profit pour réaliser une cartographie atomiquement sélective de matériaux, du catalyseur hétérogène en action aux roches réservoirs. Un ensemble de techniques in situ permettra d'accéder à la réactivité de surfaces et de nanoparticules exposées à des flux gazeux contrôlés. La combinaison des techniques synchrotrons (diffraction, absorption et fluorescence X, etc.) ou l'apport d'informations complémentaires par combinaison simultanée de techniques classiques (Raman, UV-Vis, etc.) avec les techniques du synchrotron seront enfin un atout majeur pour la caractérisation operando des matériaux.
\end{abstract}

\footnotetext{
Abstract - SOLEIL a New Powerful Tool for Materials Science - The first photons delivered by the third generation synchrotron source SOLEIL will be soon available for the scientific community. In this context, this paper presents an overview of the potentialities offered by this new machine for the study of materials. The outstanding brilliance of the SOLEIL source will enable to reduce by several orders of magnitude the data collection time for most of the synchrotron techniques (X-ray absorption spectroscopy - EXAFS, wide and small angle X-ray scattering - WAXS and SAXS, X-ray diffraction $X R D$, photoelectron spectroscopy and microscopy-XPS and PEEM, etc.) thus allowing an operando approach of catalysis processes. The spatial resolution, from a few micrometers to sub micrometer scale, accessible by microdiffraction and microspectroscopy in the wavelength range from the far IR to the hard X-rays, will provide spatial distributions of different elements (atomic and chemical state selectivity)
} 
in a material, from the working heterogeneous catalyst to the reservoir rocks. The reactivity of surfaces and nanoparticles exposed to controlled gas fluxes will be studied by several in situ techniques. Finally the combination of different synchrotron techniques (diffraction, absorption and fluorescence $X$ ) and the access to complementary information obtained through the simultaneous combination of these techniques with those routinely applied in Materials Science, such as UV-Vis or Raman spectroscopy, will offer enlarged capabilities for the operando characterization of materials.

\section{INTRODUCTION}

Since now more than thirty years, synchrotron radiation emitted by charged particles accelerated in synchrotrons and storage rings has provided the science community with photon sources gathering unique properties compared to any others: high brilliance, continuous spectrum from far infrared to hard X-rays, pulsed structure and specific polarisation features. Major advances in the machine designs together with the development of tailored magnetic insertion devices have produced the so-called third generation synchrotron radiation sources where these properties have been optimised to match the demanding research requests. SOLEIL is a third generation synchrotron radiation source of intermediate energy $(2.75 \mathrm{GeV})$ which will deliver its first photons in spring 2006 and will open its first beamlines to users at the end of 2006. The selected electron energy enables to serve the large community of the former LURE users with optimized beamlines, covering the full energy range from Infra-Red to hard X-rays, in complementarity with ESRF where high energy photon sources are primarily available.

The SOLEIL storage ring offers twenty four straight sections among which twenty one are available for insertion devices. Within the SOLEIL programme of 24 beamlines, it can be foreseen that eighteen will actually use insertion devices whereas six will be installed on bending magnets, taking full advantage of the continuous spectrum. The brilliance delivered by the undulators specially designed for the first beamlines is shown in Figure 1. The use of high harmonics may extend the range up to $30 \mathrm{keV}$ for the invacuum U20 although for these energies, the ESRF sources will be more brilliant by two to three orders of magnitude.

It should be remarked that the SOLEIL bending magnet sources also presented in Figure 1 will be as good as the ESRF ones up to about $15 \mathrm{keV}$ with a maximum brilliance of $10^{16}$ in standard units at $10 \mathrm{keV}$.

The selection of the beamlines is nearly completed since twenty two have been already positively evaluated by the SOLEIL Scientific Advisory Committee. The progressive opening to the users will take place over four years with the first ten beamlines commissioned at the middle of 2006 (socalled phase 1 beamlines) and additional sets of three beamlines opened every sixth months from 2007 to 2009 .

Brief descriptions of these beamlines in terms of energy range and main scientific goals are summarized in Tables 1 to 3. It should be remarked that in terms of coverage of broad

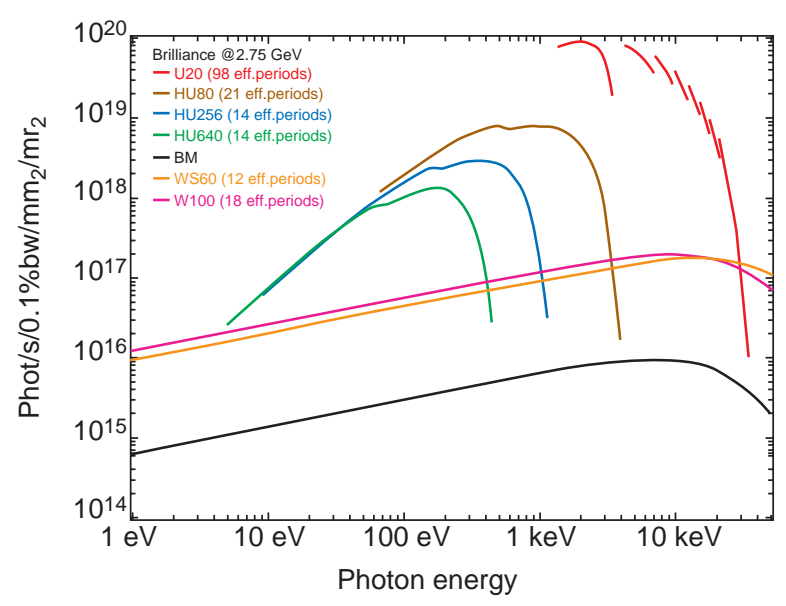

Figure 1

Brilliance calculated for a series of SOLEIL sources: five types of undulators to be installed on the phase 1 beamlines, several harmonics are displayed for each undulator, HU stands for helical undulators enabling to tune the beam polarisation; two types of wiggler sources considered for a high energy beamline, and bending magnets. Courtesy of Olivier Marcouillé.

disciplines for this set of beamlines, the following rough partition appears: Physics $25.5 \%$, Physical Chemistry $15.5 \%$, Chemistry $15.5 \%$, Biology $20.5 \%$, Geosciences $10 \%$, Environment 5\%, Astrophysics 5\% and Metrology $2.5 \%$. Among these beamlines, a large number offers outstanding potentialities for advanced materials studies, putting the emphasis either on electronic or structural or vibrational properties which are crucial for the deep understanding of chemical and catalytic processes. In this respect, SOLEIL should be the facility with the largest panel of techniques to tackle the variety of fundamental and applied issues. As will be shown in the next sections, SOLEIL will enable not only to pursue the very successful programme which has been accomplished at LURE using X-ray absorption spectroscopy, small and wide angle diffuse scattering, electron spectroscopies, infra-red spectroscopy and microscopy but also will open new routes towards spatially resolved experiments with micrometer and nanometer resolution and time resolved experiments on various significant time scales, from the "low" kinetics in the ms range to the ultra-fast phenomena in the picosecond and possibly femtosecond range. New opportunities for in situ experiments bridging the so-called 
TABLE 1a

The first beamlines to be opened in 2006

\begin{tabular}{|c|c|c|c|}
\hline \multicolumn{2}{|c|}{$\begin{array}{l}1 \text { VUV BL (HU 640) } \\
\text { DESIRS }\end{array}$} & $\begin{array}{l}(5-40 \mathrm{eV}) \\
\text { L. Nahon, G. Garcia }\end{array}$ & Spectroscopy and photochemistry on diluted matter \\
\hline $\begin{array}{l}2 \text { IR BL } \\
\text { SMIS } \\
\text { AILES }\end{array}$ & Dipole edge & $\begin{array}{l}\text { + constant field } \\
\text { P. Dumas } \\
\text { P. Roy }\end{array}$ & $\begin{array}{l}\text { Mid IR Microscopy }(2.5-50 \mu \mathrm{m}) \\
\text { Far IR Spectroscopy }(10-200 \mu \mathrm{m})\end{array}$ \\
\hline $\begin{array}{l}2 \text { Soft X-ray } \\
\text { CASSIOPEE } \\
\quad(\text { HU } 256+ \\
\text { TEMPO } \\
\quad(\text { HU } 80+\text { H }\end{array}$ & $\begin{array}{l}\text { BL } \\
\text { J } 40)\end{array}$ & $\begin{array}{l}(10-1000 \mathrm{eV}) \\
\text { A. Taleb, F. Bertran, P. Lefèvre } \\
(60-1500 \mathrm{eV}) \\
\text { F. Sirotti, M. Izquierdo (p. doc), } \\
\text { F. Rochet (associé) }\end{array}$ & $\begin{array}{l}\text { Photoemission of surfaces/interfaces: high resolution, } \\
\text { resonant, spin resolution } \\
\text { Photoemission: temporal resolution, magnetization dynamics, } \\
\text { surface reactivity }\end{array}$ \\
\hline $\begin{array}{l}3 \text { Hard X-rays } \\
(3.5-17 \mathrm{keV}) \\
(4.8-30 \mathrm{keV}) \\
(3-17 \mathrm{keV})\end{array}$ & $\begin{array}{l}\text { BL } \\
\text { PROXIMA1 } \\
\text { CRISTAL } \\
\text { SWING }\end{array}$ & $\begin{array}{l}\text { (in-vacuum U20) } \\
\text { A. Thompson, P. Legrand, E. Girard } \\
\text { S. Ravy, E. Elkaïm } \\
\text { J. Perez, O. Lyon }\end{array}$ & $\begin{array}{l}\text { Protein crystallography, coupled PX/XAS } \\
\text { Condensed matter diffraction } \\
\text { Small angle X-ray scattering: biology, soft matter, materials }\end{array}$ \\
\hline $\begin{array}{l}3 \text { Hard X-rays } \\
(3-25 \mathrm{keV}) \\
(4-40 \mathrm{keV}) \\
(3.5-23 \mathrm{keV})\end{array}$ & $\begin{array}{l}\text { BL } \\
\text { DiffAbs } \\
\text { SAMBA } \\
\text { ODE }\end{array}$ & $\begin{array}{l}\text { (bending magnet) } \\
\text { D. Thiaudière, A. Somogyi } \\
\text { V. Briois, E. Fonda, S. Belin } \\
\text { F. Baudelet, A. Congeduti }\end{array}$ & $\begin{array}{l}\text { Coupled X-ray absorption and diffraction } \\
\text { Scanning energy XAS; QUICK-EXAFS } \\
\text { Dispersive X-ray absorption spectroscopy }\end{array}$ \\
\hline
\end{tabular}

TABLE $1 b$

LUCIA, the very first SOLEIL beamline, opened at SLS (Switzerland) in summer 2004, to be transferred back to SOLEIL in 2008

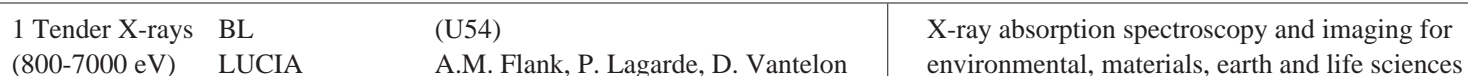

pressure gap will be offered with surface X-ray diffraction, a facility only present on one beamline at ESRF and possibly with electron spectroscopy pioneered at the Advanced Light Source (Berkeley-USA).

A selection of methods, available on the SOLEIL beamlines, is presented in the following from hard to tender and soft X-rays and finally infrared characterizations. Although the emphasis has been put on their assets for catalysis issues, the selected beamlines and many others presented in Tables 1 to 3 offer outstanding capabilities for a fine analysis of the physics and chemistry of materials.

\section{HARD X-RAYS METHODS}

\subsection{Absorption Spectroscopy}

X-ray Absorption Spectroscopy (XAS) is an element-specific probe allowing local structural and electronic information to be obtained from a diverse range of systems - solid, liquid or gas - and for atomic concentrations of the target element ranging from a few ppm to the pure element. Its use allows the experimentalist to validate elaboration processes of samples or to connect the measured structural or electronic characteristics to relevant properties, e.g. for catalysis the catalytic activity. The XAS measurement can be made in static or quasi-static working mode either:

- on ex situ already prepared samples with a controlled variation of the preparation parameters;

- or on samples presenting an in situ controlled evolution of their physical and chemical properties.

The high intensity delivered by synchrotron sources is essential for reducing data collection time thus enabling true time-resolved studies of dynamic processes, like phase transitions, catalytic reactions, or more generally sample evolutions induced by temperature, pressure, etc. Here, one can speak of a dynamic working mode.

Two beamlines at SOLEIL will be specifically dedicated to XAS: the scanning energy SAMBA beamline and the energy dispersive ODE beamline. These beamlines should offer complementary potentialities for the study of heterogeneous catalysts as described hereafter.

\subsubsection{The SAMBA Beamline}

SAMBA - for Spectroscopy Applied to Materials Based on Absorption-will be the dedicated energy-scan X-ray 
TABLE 2

Beamlines to be opened in 2007

\begin{tabular}{|c|c|c|}
\hline $\begin{array}{l}1 \text { UV- VUV BL (BM) } \\
\text { DISCO }\end{array}$ & $\begin{array}{l}(1-20 \mathrm{eV}) \\
\text { M. Refregiers, F. Wien et al. }\end{array}$ & $\begin{array}{l}\text { CD in biology; mass spectroscopy of hydrophobic systems; } \\
\text { confocal imaging (fluorescence, time-resolved fluorescence) }\end{array}$ \\
\hline $\begin{array}{l}4 \text { Soft X-rays BL } \\
\text { PLEIADES } \\
\qquad(\text { HU } 80+\text { HU } 256)\end{array}$ & $\begin{array}{l}(10-1000 \mathrm{eV}) \\
\text { C. Miron }\end{array}$ & $\begin{array}{l}\text { Physical chemistry (inner shells) diluted matter: atoms, ions, } \\
\text { molecules, aggregates }\end{array}$ \\
\hline $\begin{array}{l}\text { ANTARES } \\
\qquad(\mathrm{HU} 256+\mathrm{HU} 60)\end{array}$ & $\begin{array}{l}(10-900 \mathrm{eV}) \\
\text { M.C. Asensio, J. Avila }\end{array}$ & Fermi surface mapping with spin analysis \\
\hline $\begin{array}{l}\text { MICROFOCUS } \\
\qquad(\text { HU } 80+\text { HU50) }\end{array}$ & $\begin{array}{l}(50-1500 \text { eV) } \\
\text { M. Sacchi, R. Belkhou, C. Hague } \\
\text { (associé) }\end{array}$ & $\begin{array}{l}\text { High flux and microfocusing for imaging, inelastic scattering, resonant } \\
\text { magnetic scattering XRMS, RIXS, XPEEM (ELETTRA 2003-2006) }\end{array}$ \\
\hline $\begin{array}{l}\text { DEIMOS } \\
\qquad(\mathrm{U} \text { under study) }\end{array}$ & $\begin{array}{l}(350-2000 \mathrm{eV}) \\
\text { P. Ohresser, P. Sainctavit } \\
\text { (associé) }\end{array}$ & XMCD and XMLD, with microfocus option \\
\hline $\begin{array}{l}\text { Hard X-rays BL (U20) } \\
\text { PROXIMA2 }\end{array}$ & $\begin{array}{l}(4-17 \mathrm{keV}) \\
\text { W. Shepard }\end{array}$ & Protein crystallography tiny crystals \\
\hline $\begin{array}{l}\text { Hard X-rays BL } \quad(B M) \\
\text { MARS }\end{array}$ & $\begin{array}{l}(5-30 \mathrm{keV}) \\
\text { B. Sitaud }\end{array}$ & Diffraction and absorption on radioactive samples \\
\hline
\end{tabular}

TABLE 3

Beamlines to be opened in 2008

\begin{tabular}{|c|c|c|}
\hline Hard X-rays BL (wiggler) & $(10-50 \mathrm{keV})$ & High pressure and high temperature diffraction. \\
\hline ID $3 \mathrm{C}$ & J.P. Itié, A. Polian (associé) et al. & High energy diffraction \\
\hline $\begin{array}{l}\text { Hard X-rays BL, } \\
\quad \text { (in-vacuum undulator) }\end{array}$ & $(4-20 \mathrm{keV})$ & Diffraction on 2D systems (hard and soft condensed matter); \\
\hline SixS & $\begin{array}{l}\text { Y. Garreau, A. Coati, } \\
\text { V.H. Etgens (associé) }\end{array}$ & 2D magnetic diffraction; catalysis under high pressure \\
\hline $\begin{array}{l}\text { Hard X-rays BL, } \\
\text { (undulator with tunable polarization) } \\
\text { SIRIUS }\end{array}$ & $\begin{array}{l}(2-10 \mathrm{keV}) \\
\text { P. Fontaine, J.M. Tonnerre } \\
\text { (associé) et al. }\end{array}$ & Resonant diffraction on soft interfaces and magnetic materials \\
\hline $\begin{array}{l}\text { Hard X-rays BL, } \\
\quad \text { (in-vacuum undulator) } \\
\text { GALAXIES }\end{array}$ & $\begin{array}{l}(3-12 \mathrm{keV}) \\
\text { J.P. Rueff, A. Shukla (associé) } \\
\text { et al. }\end{array}$ & High resolution inelastic X-ray scattering, high energy photoemision \\
\hline
\end{tabular}

absorption beamline at SOLEIL available for a large and varied scientific community from physics to chemistry, biology and environmental science. A detailed presentation of the beamline has been already published in the Proceeding of the XII ${ }^{\text {th }}$ International Conference of XAFS held in Malmo (June 2003) [1]. Only the main attractive characteristics for the Materials Science community will be pointed out herein. The geometry and optics of the beamline have been designed to deliver the highest flux available at the exit of a SOLEIL bending magnet by using cylindrically bent mirrors and a sagitally focusing double crystal monochromator for focusing the beam in the vertical and horizontal planes, respectively. The optical scheme is then very similar to the one which can be found on the FAME beamline [2] at the ESRF or previously on the $\mathrm{H} 10$ beamline [3] at LURE. Due to the high flux available (typically $10^{12}$ and $5.10^{11} \mathrm{ph} / \mathrm{s}$ at 5 and $20 \mathrm{keV}$, respectively in a $200 \times 200 \mu \mathrm{m}^{2}$ spot at the sample position), this set-up configuration will concern experiments aiming to characterize dilute species such as minor components of heterogeneous catalysts. We should expect a shift of the detection limit by a factor 10 to 100 compared to the performances available at LURE depending on the photon energy. Besides this so-called SAMBA high-flux operation mode, we have taken care to provide also the users' community with a Quick-EXAFS set-up. This will be done using a dedicated Quick-EXAFS monochromator installed 
downstream the sagitally focusing monochromator. The design of this monochromator is part of a collaboration with the group of Pr R. Frahm from the Wuppertal University (Germany) [4]. The expected performances for time-resolved studies should be of some ten ms for XANES acquisitions and from a few hundred $\mathrm{ms}$ to a few $\mathrm{s}$ for EXAFS data collection depending on the concentration of the element. Although the time resolution of Quick-EXAFS on SAMBA should be slightly less than the one available on the dispersive EXAFS beamline ODE, due to the intrinsic use of sequential data acquisition of a scanning energy XAS spectrometer, the data acquisition is not restricted to the transmission mode for a thin but concentrated sample. Indeed, the fluorescence yield (FY) and the photoinduced current (total electron yield, TEY) will be two alternative detection modes enabling the time resolved characterization of catalysts with a small loading of active species and of supported catalysts and thus allowing more realistic conditions for the study of catalytic activity. For example, the development of a TEY cell capable of operating under catalytic conditions up to $80 \mathrm{~atm}$ has been reported [5]. The high-flux operation mode and the Quick-EXAFS mode will be available alternatively on SAMBA.

The SAMBA beamline is designed to offer a permanent access to the 4-43 keV energy range using $\mathrm{Si}(220)$ crystals for the sagitally focusing monochromator or $\mathrm{Si}(111)$ and $\mathrm{Si}(311)$ crystals, which can be exchanged by a lateral translation for the Quick-EXAFS monochromator. These choices allow relatively fast change of the beamline working energy since no vacuum breaking in the optics vessel is required.

The energy range covered by SAMBA concerns the most important industrial heterogeneous catalysts and applications: metal oxides or mixed-metal oxides $\left(\right.$ e.g. $\left.\mathrm{V}_{2} \mathrm{O}_{5} / \mathrm{TiO}_{2}\right)$ for the partial or total oxidation of hydrocarbons, metals and alloys, generally in a supported state $\left(\right.$ e.g. $\left.\mathrm{CuO} / \mathrm{ZnO} / \mathrm{Cr}_{2} \mathrm{O}_{3}\right)$ for the synthesis of methanol from syngas $\left(\mathrm{CO}\right.$ and $\left.\mathrm{H}_{2}\right)$, supported bimetallic nanoparticles for the selective hydrogenation of unsaturated hydrocarbons (e.g. $\mathrm{CuRu}$ or $\mathrm{PdRu}$ ) or for automotive catalytic converters (e.g. PtRh), zeolitic microporous solids (rare-earth catalysts on zeolite Y) for the cracking and hydrocracking of heavy oils, metal-ion substituted zeolites or analogues for the conversion of methanol to alkenes, etc. Several recent publications have reviewed the application of XAS to the study of heterogeneous catalysts under operating conditions [6-8]. In particular J. Lynch in 2002 [7] and D. Bazin et al. in 2003 [8] have given an assessment of the experiments carried out at LURE the past ten years within the collaboration between LURE and the IFP. Clearly one of the missions of the SAMBA beamline is to offer the same possibilities as those available at LURE for in situ studies of catalysts. The policy of SAMBA is to propose a standard access to the catalysis community with the design and construction of at least one new catalytic reactor capable of maintaining the catalyst under pressure of reactive gases at a controlled temperature in order to substitute the old furnaces available at LURE. But clearly the design of reactors for specific applications and the adaptation of a gas chromatograph or a mass spectrometer for analysis purposes of the reaction products should be a part of development and investment from the users' community itself. A working group, identified as the socalled CARAYSS network [9], has brought together most of the French laboratories of catalysis in order to define a common scientific project in which common needs in standard equipment would be pointed out for reproducing, at the beamline, reaction conditions as close as possible to those existing in the home laboratory.

Besides the cells allowing the study of the catalyst in operating conditions, extended efforts were done on the LURE D44 beamline in the past two years for allowing the use of several complementary techniques simultaneously with the XAS. The access to coupled information on the same material offers great advantages with respect to separate experiments, not only to spare time but also to get rid of errors due to differences in sample environment, thermal history, aging, temperature and preparation conditions. Even more important is the possibility to resolve ambiguities in the understanding of phase transition mechanisms by allowing accurate determination of the sequence of the events by the different techniques. Such combinations of techniques are clearly a prerequisite for fully making the XAS technique an operando spectroscopy for the catalyst characterization. Indeed, in many cases, XAS alone is unable to provide a unique solution for the proposed structure.

This complementarity is illustrated in Figure 2 with the example of the rehydratation of a calcinated $5 \mathrm{wt} \%$ $\mathrm{Mo} / \mathrm{Al}_{2} \mathrm{O}_{3}-\mathrm{SiO}_{2}$ supported catalyst [10] which is a potential candidate for the desulfurisation of petroleum feedstocks. The experimental arrangement used for this study is displayed in Figure 3. XAS analysis of the supported catalyst reveals upon rehydratation a change of the local order around Mo (Fig. 2a) from isopolymolybdic species $(\mathrm{t}=0)$ to aluminomolybdate entities as evidenced by the comparison with the $\left[\mathrm{Al}(\mathrm{OH})_{6} \mathrm{Mo}_{6} \mathrm{O}_{18}\right]^{3-}$ ionic reference (labelled hereafter $\mathrm{AlMo}_{6}$ ). Additional information obtained by Raman spectroscopy (Fig. 2b) clearly evidences the presence of the $\mathrm{MoO}_{3}$ phase during the first $18 \mathrm{~h}$ of kinetics which was not detected by XAS due to its low content in the mixture. The formation of $\mathrm{AlMo}_{6}$ entities is also clearly and unambiguously shown. This Raman result is important since it allows the experimentalist to introduce with confidence a Mo-Al contribution for simulating the EXAFS signal related to the second peak of the Fourier Transform. Without the support of the Raman data, the addition of such Mo-Al contribution could be considered as a fitting trick, insofar as satisfactory fit is already achieved by considering Mo-Mo contributions only. 

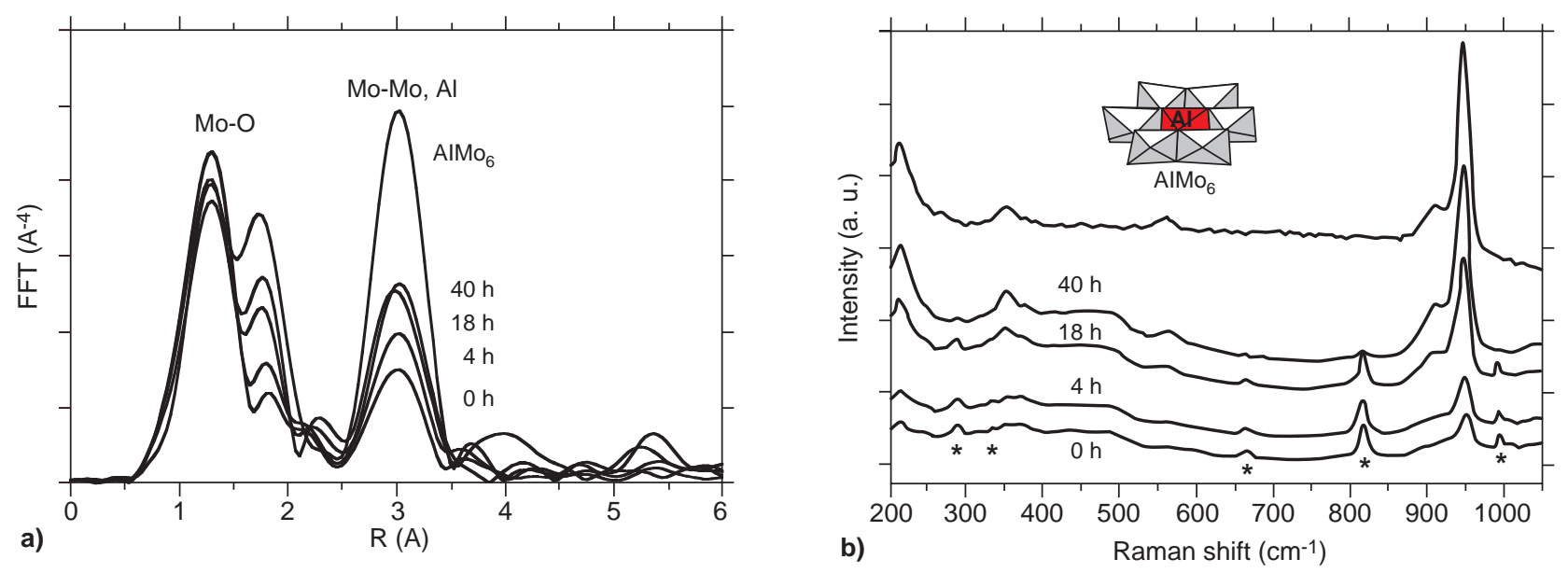

Figure 2

Study of the room temperature rehydration of a calcinated $\mathrm{Mo} / \mathrm{Al}_{2} \mathrm{O}_{3}-\mathrm{SiO}_{2}$ supported catalyst [10] by a) XAS and b) by Raman. The spectrum of the aluminomolybdate ion labelled $\mathrm{AlMo}_{6}$ is presented for comparison. The stars are related to characteristic Raman lines of $\mathrm{MoO}_{3}$.

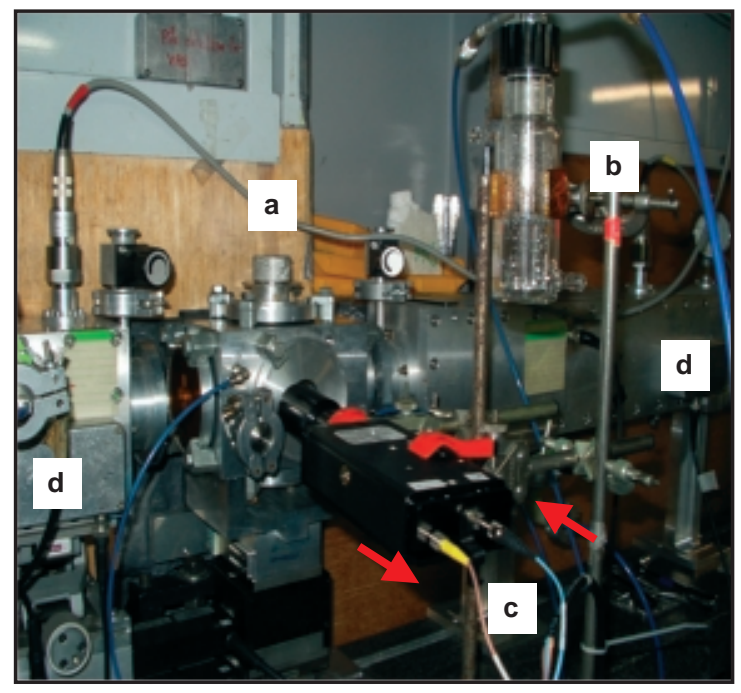

Figure 3

Experimental arrangement for the simultaneous recording of XAS and Raman data on D44 station at LURE used for the in situ study of the rehydration of a calcinated $5 \mathrm{wt} \% \mathrm{Mo} / \mathrm{AlO}_{3}^{-}$ $\mathrm{SiO}_{2}$ supported catalyst. Reaction cell a) containing a selfsupported pellet of the catalyst under a stream of watersaturated oxygen b), Raman probehead c) used for the excitation by a NIR laser diode at $785 \mathrm{~nm}$ and for the collection of the Raman signal, ionisation chambers d) for XAS detection in transmission.

The potentialities offered by the combinations of XAS with UV-Vis, Raman spectroscopies or Differential Scanning Calorimetry have been fully presented in [10] aiming to characterize in a quasi static working mode on the D44 station a variety of materials (molecular magnets, precursors of catalysts, or sol-gel materials). Very recently, the ability to use the same complementary techniques for the study of dynamical processes has been demonstrated, first on the LURE dispersive beamline D11 [11] in view of characterizing the formation of $\mathrm{ZnO}$ colloidal nanoparticles in solution and second by using the Quick-EXAFS monochromator developped by Pr Frahm's group. For the latter, two techniques, UV-Vis and Raman, were combined with Quick-XANES to study the oxidation of ethanol by ceric ions [12] in $\mathrm{HNO}_{3}$ media allowing to obtain consistent and reliable information on the kinetic of oxidation as the relative proportion of $\mathrm{Ce}^{4+}$ and $\mathrm{Ce}^{3+}$ together with the composition of the coordination spheres of each cation (nitrate, ethanol and water) as illustrated in Figure 4.

Besides the different combinations (UV-Vis, Raman and DSC) available at SOLEIL thanks to a transfer from LURE, the possibility of recording (simultaneously or not with the $\mathrm{X}$-ray absorption spectrum) an X-ray powder diffraction pattern will be offered [13]. Such development has had in the past a considerable impact on heterogeneous catalysis as reviewed recently by Clausen [14]. It will allow the experimentalist to obtain short range and long range information from the same sample under identical conditions.

\subsubsection{The ODE Beamline}

The classical method of recording absorption spectra is the step by step measurement of the absorption coefficient for each energy point, as achieved on the SAMBA beamline. Another approach was proposed by Matsuchita [15], the energy dispersive EXAFS scheme which uses a bent monochromator to eliminate the stepwise scanning of the Xray energy. The continuous change of the incidence angle along the bent crystal opens an energy range in the Bragg reflected beam. The correlation between position and energy 


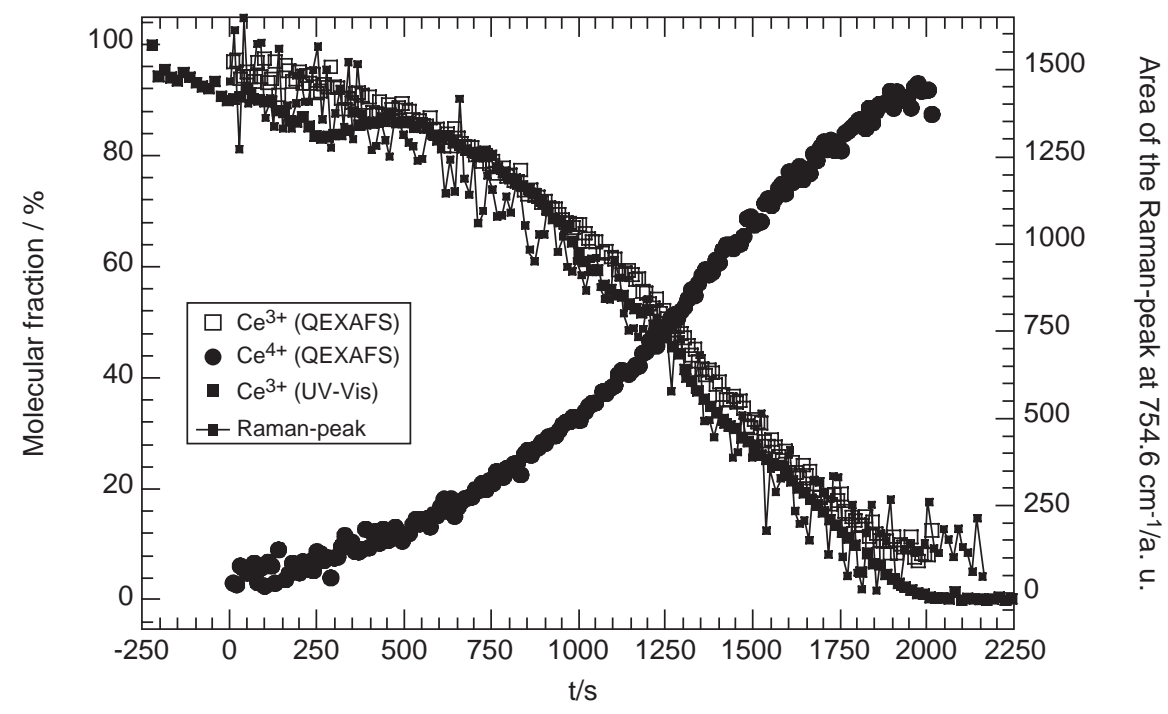

Figure 4

Molar fractions of $\mathrm{Ce}^{4+}$ and $\mathrm{Ce}^{3+}$ determined simultaneously by Quick-XANES and UV-Vis spectroscopy during the kinetic of oxidation of ethanol. The variation of the intensity of the Raman peak at $745.6 \mathrm{~cm}^{-1}$ related to associated nitrate anions indicates that upon reduction of $\mathrm{Ce}^{4+}$ into $\mathrm{Ce}^{3+}$ coordinated nitrate anions are released in solution [12].

of the X-ray is exploited thanks to a position sensitive detector. This method was adapted at LURE on the D11 beamline as early as 1981 [16] and fully opened to users from 1985 to 2003. The dispersive set-up has been upgraded twice; the last upgrade was completed in 1996 with the ambition of building a competitive experiment, to be transferred at SOLEIL.

One of the first ideas promoting the dispersive mode development was the possibility to perform time resolved EXAFS measurements and indeed the first experiments were concerned with the kinetics of the doping process in conducting polymers [17]. The main assets of dispersive XAFS are the focusing optics, the great stability during the measurements due to the absence of any mechanical movement, which warrants that the same part of the sample is probed while recording single or multiple spectra and the short acquisition time (few ms). These three advantages allow the study of small samples $(500 \mu \mathrm{m}$ at LURE, $40 \mu \mathrm{m}$ at SOLEIL), to follow kinetics, and to perform experiments with a signal to noise ratio as good as $10^{5}$ thus enabling the collection of very small signals by differential techniques. The limitation of this scheme is the impossibility to perform XAS measurements in fluorescence or TEY mode.

In the vast domain of chemical reactions, where characteristic times are found between femtoseconds and hours. Fast ms EXAFS measurements can thus provide either a short integrated picture of faster kinetic, like those involving electron transfer in coordination chemistry or homogeneous catalysis, or a fine characterization of all steps of slower kinetics, like those encountered in solid state transformation, in particular in heterogeneous catalysis. At the present time, dispersive XAFS is the unique way of collecting EXAFS spectra in a sufficient energy range in a few ms, contrary to the Quick EXAFS (QEXAFS) where characteristic times are measured in hundreds of milliseconds [18].

Today EXAFS measurements are currently achieved on the insertion device ESRF beamline ID24 in the ms range [19] and some results have been obtained in the $\mu$ s-range [20]. Although the bending magnet source selected for ODE is less brilliant than the ID24 undulator, the access to the ms scale will be easily offered to the user's community, associated to a guarantee of a maximum stability and reliability.

Some studies of kinetics in chemistry have been already undergone in the past with the time resolution of $100 \mathrm{~ms}$. We can for example mention in situ studies of corrosion or chemical reaction in super-critical water presenting theoretical and industrial interests [21]. One can also mention the heterogeneous catalysis studies, with in situ characterization $[22,23]$, and sol-gel processes, where parallel measurements with small angle $\mathrm{X}$-ray scattering give important information on the formation of $\mathrm{ZnO}$ nanoparticles [11].

Solid catalysts accelerate chemical reactions. XAS spectroscopy allows studying real catalyst under practical reaction conditions, which means that temperature and pressure parameters have to be controlled during the data acquisition. The knowledge of the oxidation state of the reactants and the coordination of the absorbing site in the formed species during the catalytic process helps to determine the best reaction conditions. There are usually two domains of catalysis: homogeneous and heterogeneous. In 
the first case, in situ reaction study needs to use a stoppedflow with a variable temperature solution cell. In the second case, a reactor with variable temperature and gas pressure is used. These two kinds of processes will be studied at SOLEIL on the dispersive beamline, however, such goal will only be reached with strong collaborations from laboratories where these technologies are well developed. The high homogeneity of our focus point, which is a requirement for high-pressure measurements, opens the possibility to perform heterogeneous catalysis studies [24, 25]. Furthermore the use of several complementary techniques simultaneously with the XAS mentioned for the SAMBA beamline will be also possible on the ODE beamline, with faster acquisition time for kinetics measurements but without the fluorescence and the TEY modes for diluted species.

\subsection{Coupled Absorption-Diffraction}

As mentioned in Section 1.1.1, complementing the local structure information given by XAS by data on the long range order can be of primary importance for a full characterization of material transformations. The DiffAbs (Diffraction-Absorption) beamline of SOLEIL partially resulting from the transfer of $\mathrm{H} 10$ [3], the last beamline built around the DCI storage ring at LURE, is specifically optimised to fulfil this purpose. The H10 beamline is described in this review by the article of Gailhanou et al. with the emphasis on catalysis issue and the example of Xray diffraction studies of zeolite samples at low energy. In the future, DiffAbs will be dedicated to the structural study of a great variety of materials combining, if required, X-ray diffraction (XRD), X-ray fluorescence (XRF) and X-ray absorption spectroscopy (XAS) using either macro- or microbeam for excitation.

DiffAbs will offer the possibility of studying the short and medium-range characteristics of materials by the almost simultaneous combination of X-ray absorption spectroscopy (XAS) and wide angle scattering (WAXS). Resonant diffraction spectroscopy, such as Diffraction Anomalous Fine Structures (DAFS), will be applied to obtain site- and chemistry specific information. As an example the investigation of epitaxy stabilised CaF2-type ternary $\mathrm{Co}_{1-\mathrm{x}} \mathrm{Fe}_{\mathrm{x}} \mathrm{Si}_{2}$ silicides on $\mathrm{Si}(111)$ samples is cited [26]. More generally, the study of anomalous diffraction/scattering (variation of the scattering cross section in the vicinity of an absorption edge of the probed element) will be available at the beamline for the user's community [27]. Time-resolved X-ray diffraction measurements (millisecond measurement time) will make the investigation of fast kinetics possible, for instance phase transitions or self-propagating high temperature synthesis [28]. The study of thin films and interfaces, in particular to determine their mechanical properties (strain measurements and stress determination), will be an important application field of the DiffAbs beamline [29, 30].
The $\mu$-XRF, $\mu$-XRD and $\mu$-XAS techniques will also be offered at the beamline. Scanning $\mu$-XRF will give information about the spatial distribution of the major and trace elements and their inter-element correlation within the investigated samples with $\sim 10 \mu \mathrm{m}$ resolution. The simultaneous combination of scanning $\mu-\mathrm{XRF}$ and $\mu-\mathrm{XRD}$ will give insight into the possible correlation between the variation of the elemental composition and crystalline structure. The large energy range available at DiffAbs will ensure the XAS study of the $\mathrm{K}$ absorption-edges of elements between $\mathrm{K}$ and $\mathrm{Zr}$ and the L-edges between $\mathrm{Ru}$ and $\mathrm{U}$. The combination of $\mu$-XAS with $\mu$-XRF and/or $\mu$-XRD offers the possibility of investigating the micro-scale variation of the chemical speciation of an element in the function of the elemental composition and crystalline structure of the sample matrix [31].

All these techniques will be used in the main scientific field of the beamline dedicated to the study of the behaviour of materials at high and very high temperatures (from room temperature up to $3000^{\circ} \mathrm{C}$ ). More generally, these analytical possibilities and their combination will provide useful research tools in the fields of materials sciences and also in catalysis research.

\section{Specification of the Beamline and Sample Environments}

DiffAbs will be situated at the D13-1 bending magnet of the SOLEIL storage ring. Focused, monochromatic beam ("normal mode", energy range: $3-23 \mathrm{keV}$ ) will be provided by two bent, Rh-coated, mirrors and a double-crystal $\mathrm{Si}(111)$ sagitally focusing monochromator situated in the optic hutch. A microbeam of several microns size ("microbeam mode", energy range: 3-19 keV) will also be available by utilizing an additional, secondary focusing optics, e.g. a Kirkpatrick-Baez (KB) mirror-pair in the second, experimental hutch. The characteristics of these two operation modes are summarized in Table 4. In the microbeam mode smaller spot-size can also be achieved at the cost of flux by defining a smaller secondary source by the beamline slits.

In the experimental hutch a 6 circle kappa diffractometer -foreseen to be used for most of the experiments-will be installed. It will consist of two concentric goniometers; a 4 circle one ensures the orientation of the sample, while 2 additional circles will be used for the positioning of the detector. This kappa geometry has been chosen in order to improve the mechanical performances of the goniometer. It also has the advantage of ensuring a large free volume for the installation of heavy and voluminous samples and their environment.

A multielement solid state detector is foreseen for X-ray fluorescence (XRF) and EXAFS measurements (in fluorescence mode). This detector will be located at $90^{\circ}$ with respect to the direction of the incoming $\mathrm{X}$-ray beam. Scanning $\mu$-XRF measurements will be performed in microbeam mode by raster scanning the sample in the 
TABLE 4

General characteristics of the different beam modes available at DiffAbs

\begin{tabular}{|c|c|c|}
\hline \multirow[b]{2}{*}{ Parameters } & \multicolumn{2}{|c|}{ Monochromatic beam modes } \\
\hline & "normal" & “microbeam” \\
\hline Spectral range (keV) & $3-23$ & $3-19$ \\
\hline Relative energy resolution & $\sim 10^{-4}$ & $\sim 10^{-4}$ \\
\hline $\begin{array}{l}\text { Beam size } \\
\left(\mathrm{HxV}, \mathrm{FWHM} \text { in } \mathrm{mm}^{2}\right)\end{array}$ & $0.140 \times 0.240$ & $0.014 \times 0.011$ \\
\hline $\begin{array}{l}\text { Flux } \\
\left(\mathrm{ph} . \mathrm{s}^{-1}\right)\end{array}$ & $10^{12}-10^{13}$ & $10^{10}-10^{11}$ \\
\hline $\begin{array}{l}\text { Divergence } \\
(\mathrm{mrad})\end{array}$ & $\begin{array}{c}\text { varying } \\
\mathrm{H}=7.14-2.90 \\
\mathrm{~V}=0.54-0.20\end{array}$ & $\begin{array}{c}\text { varying } \\
\mathrm{H}=2.87-0.98 \\
\mathrm{~V}=6.22-2.14\end{array}$ \\
\hline
\end{tabular}

focused beam. The $\mu$-XRF technique will be combined with scanning $\mu$-XRD by adding a $2 \mathrm{D}$ diffraction camera to the set-up.

Transmission EXAFS experiments will be carried out both in the normal and microbeam modes by inserting a monitor after the sample in order to measure the transmitted intensity.

A furnace developed for the $\mathrm{H} 10$ beamline will be transferred to DiffAbs. This furnace operates in air at temperatures up to $500^{\circ} \mathrm{C}$ and in vacuum up to $800^{\circ} \mathrm{C}$. A new furnace working up to $2000^{\circ} \mathrm{C}$ in vacuum or in controlled atmosphere is foreseen in collaboration with the CRMHT (Orléans). Both furnaces will be used for the study of polycrystalline samples, such as powders and thin films. Furthermore, the original device applied at H10 for the study of oxides in molten state [32, 33] will be upgraded by including two $\mathrm{CO}_{2}$ power lasers for a homogeneous heating of the sample. The contact between the liquid sample and the sample holder will be avoided by aerodynamic levitation. In that case, the spherical sample can be maintained at a stable position in a neutral $(\mathrm{Ar}, \mathrm{He})$ or reagent $\left(\mathrm{O}_{2}, \mathrm{H}_{2}\right)$ gas flow. For the study of metal alloys in molten and undercooled states another device is under development in the framework of a French-German collaboration (CRMHT, SOLEIL and the DLR in Cologne). The sample will be heated by a radiofrequency generator in a specific chamber designed for aerodynamic levitation [34]. Both XAS and XRD measurements are planned to be performed with this sample chamber.

\subsection{Grazing Incidence Surface Diffraction}

The Surface Diffraction beamline SixS (Surface interface x-ray Scattering) [35] will be devoted to the study of surfaces, interfaces and nanostructures of different materials in various environments, exploiting the grazing incidence diffusion and diffraction of X-rays. The under-vacuum undulator source U20 delivers a beam in the $5-20 \mathrm{keV}$ energy range, with high flux and low divergence, allowing one to well-define the grazing incidence angle, which is essential for the optimisation of the signal/noise ratio, being the surface signals very weak.

The beamline has an experimental configuration, which offers a rich combination of X-ray scattering techniques: Grazing Incidence X-Ray Diffraction (GIXD) in vertical or horizontal geometries, Grazing Incidence Small Angle X-ray Scattering (GISAXS) and X-ray reflectivity. Two instruments will be implemented to satisfy the needs of these techniques: a diffractometer in Ultra High Vacuum (UHV) that will allow the study of solid surfaces, interfaces, nanometric objects and growth mechanisms; a second diffractometer will be able to host different sample environments, like electrochemical cells, Langmuir trough, catalytic chambers, etc. for the study of interfaces (liquid-liquid, liquid-solid, solid-gas).

Surface X-ray diffraction under grazing incidence (GIXD) is nowadays well established in the panel of surfaces and interfaces structural probes. The structural information is a key step for a complete understanding of the physical and chemical properties of interfaces involved in modern materials science and technology. This technique has been applied successfully to address the mechanisms involved in heterogeneous catalysis, where information can be obtained on the reactive site and the reaction pathway, thus identifying the intermediary steps of reaction. In particular, surface studies help to characterize the chemically adsorbed species participating in the reaction. However, such studies often require techniques adapted either to ultra high vacuum or at least to very low pressures: low energy electron diffractionLEED, near field microscopy-STM, electron spectroscopyXPS/AES, vibrational spectroscopy like HREELS, infra-redIRRAS.

Nevertheless, the studies of gas adsorption and surface reactivity in UHV are far from the "real" conditions of a catalytic reaction, and the results obtained under UHV can hardly be extrapolated to the real conditions of reactions, which occur in a pressure range 8 to 10 orders of magnitude higher. Indeed, the reorganisation of a surface in the presence of a gas and the real nature of the intermediate phases produced during the catalytic reaction can be very different from those observed in ultra-high vacuum or at low pressures. Only the most strongly bonded species are expected to remain under ultra-high vacuum whereas the weakly bonded states may desorb very quickly. We know that these weakly interacting species referred to as precursors, are precisely the ones supposed to guide the reaction towards its final product. The identification of these species as well as the characterization of the active sites is thus essential for a further comprehension of the reaction mechanisms.

In "real" pressure conditions, the standard experimental tools used for surface studies in UHV can only be operated with sophisticated adaptations (see Section 2.2 for the techniques using the electrons). Recently, some results on 
catalysis and surface morphology evolutions at high pressures have been obtained by coupling STM to mass gas detectors by the groups of G.A. Somorjai [36, 37] and J.W. M. Frenken [38]. They studied the modifications induced on the surface morphology during a catalytic reaction and their observations show that the surfaces present strong difference between their structures at low and at high pressure. The surface diffraction can, in this context, fill up the gap between the low and high pressure catalytic studies. To this aim, an interesting approach has been the development of experimental chambers dedicated to catalysis. The sample surfaces, prepared using the standard UHV techniques, can then be exposed to a catalytic environment, and their structural modifications followed in situ by GIXD.

In the following we present some examples of catalytic reactions at a surface, in which the surface diffraction study could give (or has given) useful information. In 2001, K.F. Peters and collaborators [39-41] have followed the structural evolution induced by $\mathrm{CO}$ adsorbed on the (110) surface of $\mathrm{Ni}$ in a huge pressure range: from $10^{-10} \mathrm{mBar}$ to 3 Bars. They used Surface diffraction at the ID3 beamline of ESRF where they built a new chamber compatible with highpressure studies and adapted to the X-ray diffractometer. They observed that at room temperature, the high pressure and low-pressure structures were identical. Conversely, at a temperature of $130^{\circ} \mathrm{C}$, an exposure to high $\mathrm{CO}$ pressure was found to produce the reorganization of the $\mathrm{Ni}$ substrate that developed strained (111) microfacets. More recently, M. Ackermann et al. [42] have studied a catalytic reaction under "real conditions": they have investigated the production of methane from a mixture of $\mathrm{CO}$ and $\mathrm{H}_{2}$ close to atmospheric pressure using a $\mathrm{Ni}(111)$ surface as a model catalyst. The reaction products were monitored with a gas analyser and the surface structure with GIXD. They observed that at a temperature between 100 and $200^{\circ} \mathrm{C}$ a Ni ${ }_{3} \mathrm{C}$ epitaxial film develops on the surface, while no methane production occurs. At temperatures above $400^{\circ} \mathrm{C}$ a clear methane production was evidenced and no ordered carbide film was present on the surface, which presents no significant rearrangement with respect to a freshly prepared surface under UHV. M.C. Saint-Lager and coworkers [43] have performed an in situ study by GIXD of the structural evolution of the $\mathrm{Pd}_{8} \mathrm{Ni}_{92}(110)$ (Nx1) surface exposed to butadiene $\left(\mathrm{C}_{4} \mathrm{H}_{6}\right)$. They followed the modifications of the structure induced by a butadiene hydrogenation at elevated pressures under reaction conditions (room temperature, 5 mbar). Once again the data show a strong correlation between the X-ray diffraction signature of the surface structure and the reaction product analysis.

All the examples reported here show that the structural information given by the GIXD can be useful in order to determine the active sites in catalysis. Moreover, coupled with other experimental probes, like mass spectrometry, one can follow in situ evolutions of the surface structure and reaction products, either at low or at high pressures. Among the advantages presented by Surface Diffraction we can mention that it is a non-destructive technique, which can be used to probe any type of gas environment. With the high brilliance of the third generation synchrotrons, it becomes also possible to study the catalysis reactions in real time. The SixS beamline at SOLEIL will be partially dedicated to these topics. It will offer a chamber combining ultra-high vacuum and high pressures, compatible with the grazing X-ray diffraction geometry. This chamber will be equipped with the standard UHV tools for surface preparations, and will offer the possibility to subsequently expose it to high-pressure gas environments. Moreover, the diffraction study will make it possible to follow the changes of the surface structures induced by the gas exposure (reconstructions, relaxations). The beamline will be able to perform in situ Grazing Incidence Small Angle X-Ray Scattering (GISAXS) measurements [44], which will allow to follow in real time the morphology evolution of the surface during the reactions. By coupling this technique with GIXD, it will be possible to obtain a complete structural and morphological characterisation of the studied systems.

\subsection{Small Angle X-Ray Scattering (SAXS)}

In the material science field, studies are expected to develop following two directions: nanoprecipitates in the bulk and thin layers of nanomaterials [45]. In the bulk, the morphology, organization and chemical composition of the nanoprecipitates can be determined by Small Angle X-ray Scattering (SAXS). The chemical composition is obtained using the so-called "anomalous labelling" [46] (i.e. the variation of the atomic scattering factor as a function of photon energy close to the absorption edge of the investigated element). This labelling method can be applied to a variety of systems like metallic alloys, colloids, ferrofluids or polyelectrolyte gels. Moreover, the research on thin layers of nanomaterials is undergoing an explosive development because these samples play an increasing role in several technological domains like optoelectronics, non linear optics (semi-conductor or metallic nanocrystals in a dielectric matrix), catalysis [47-49] (Pt or Pd-Pt clusters for example), magnetic thin films or multi layers ( $\mathrm{Fe}$ and Co clusters in insulating or conductive nonmagnetic matrices), nano-electronics, carbon nanotubes, etc. In all cases, the nanoclusters are present in thin layers, supported or buried, and must be studied using grazing incidence techniques (GISAXS) to obtain information on the size, shape and distribution of these clusters [50-54]. The use of anomalous scattering (AGISAXS) can expand further the potential of this method by enabling one to retrieve the contribution of a given element (metallic clusters in a mesoporous silicon network, nanoclusters included in a rough layer, metals encapsulated in a network of carbon nanotubes, etc.) from the scattering pattern. 
A small angle X-ray scattering beamline (SWING) will be in operation at the SOLEIL Synchrotron facility around spring 2006 to fulfil the needs of three different fields of research: biology, soft condensed matter and material science respectively. This beamline is being built around a new generation undulator in order to provide a very strong and thin X-ray beam with a low divergence. A two-crystal monochromator will select the photon energy between $5 \mathrm{keV}$ and $20 \mathrm{keV}$, a set of two orthogonal focusing mirrors, in Kirkpatrick-Baez geometry, will then both reject harmonics and eventually focus the $\mathrm{X}$ ray beam on the sample or on the detector, with a spot size of about $100 * 300 \mu \mathrm{m}^{2}$ (which can be reduced further with slits). Different kinds of sample environment will be provided among which will be a multi sample holder to study some very thin samples (down to $500 \mathrm{~nm}$, if supported on a flat surface) under grazing incidence (GISAXS). A long evacuated tube $(6 \mathrm{~m}$ long and $1.8 \mathrm{~m}$ in diameter) will contain a $2 \mathrm{D}$ detector in order to collect the SAXS spectra. Therefore, this beamline will be able to study very small objects with a size in the range of $1 \mathrm{~nm}$ to a few $\mu \mathrm{m}$ (in transmission mode only), (see http://www.synchrotron-soleil.fr/francais/lignes/SWING.htm for more information).

Below are shown two examples of samples which were studied with the GISAXS technique at the LURE synchrotron laboratory, in order to understand their catalytic properties.

The first sample (Fig. 5) was elaborated by electron sputtering of two layers of $40 \mathrm{~nm} \mathrm{ZrO}_{2} / 0.6 \mathrm{~nm}$ Pt, sputtered at room temperature on a $\mathrm{Si}$ wafer, followed by a reduction at $400^{\circ} \mathrm{C}$. The $2 \mathrm{D}$ diffusion spectrum shows 2 diffusion lobes which are characteristic of the formation of Pt aggregates and carries the information on their size, morphology and distribution: $4 \mathrm{~nm}$ in lateral size, $3 \mathrm{~nm}$ in height and $11 \mathrm{~nm}$ in average distance. The spectrum shows also horizontal fringes due to the interferences between the $40 \mathrm{~nm}$ thick layer and the Si subtract. These kind of samples are studied because of their technological interest by LMP and LACCO laboratories at Poitiers, in order to understand the influences of the morphology and the crystallographic structure of metallic clusters, as well as the influence of the subtrate microstructure on the catalytic properties of $\mathrm{Pt}$ on $\mathrm{ZrO}_{2}$.

In Figure 6 is illustrated the case of nanoclusters of PtRh created by plasma deposit on an amorphous $\mathrm{Si}$ oxide. Depending on the elaboration conditions, the clusters present different morphologies and different sizes $(2 \mathrm{~nm}$ on the left and $8 \mathrm{~nm}$ on the right for example), with a rather low dispersion since high orders are visible on these 2D spectra. Such information is of primary importance to optimise the preparation route of performant catalysts.

The new SWING GISAXS beam line will stir up this kind of studies, since the beam intensity will be more than 5 orders of magnitude higher than the LURE one, comparable to the best ESRF experimental set ups, with a higher flexibility. It will enable the study of very dilute samples, as well as samples with many different elements which will be labelled through the use of the anomalous effect. It will have in situ heating capability (up to $600^{\circ} \mathrm{C}$ ), as well as some in depth scanning possibilities by varying the penetration angle of the $\mathrm{X}$ ray with a high precision rotation stage. The large place devoted to the sample environments on the beamline will accommodate future experimental set ups

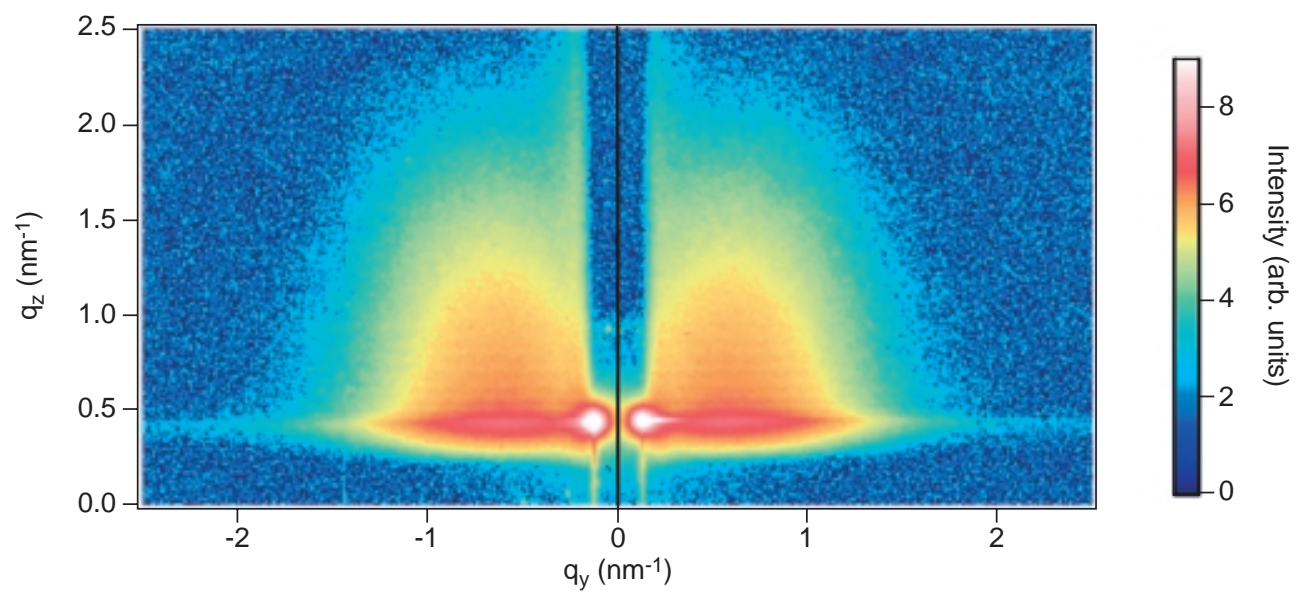

Figure 5

2D map of the scattering from a sample prepared by electron sputtering of $2 *\left(40 \mathrm{~nm} \mathrm{ZrO}_{2}\right.$ and $0.6 \mathrm{~nm}$ of Pt $)$ and reduction at $400^{\circ} \mathrm{C}$. The long vertical beam stop located at $\mathrm{q}_{\mathrm{y}}=0$ prevents the detector from being damaged by either the direct beam (the two white dots are remainders), or by the total reflection. The position and size of the two lobes allow a determination of the size and geometry of the corresponding clusters. Courtesy of David Babonneau. 

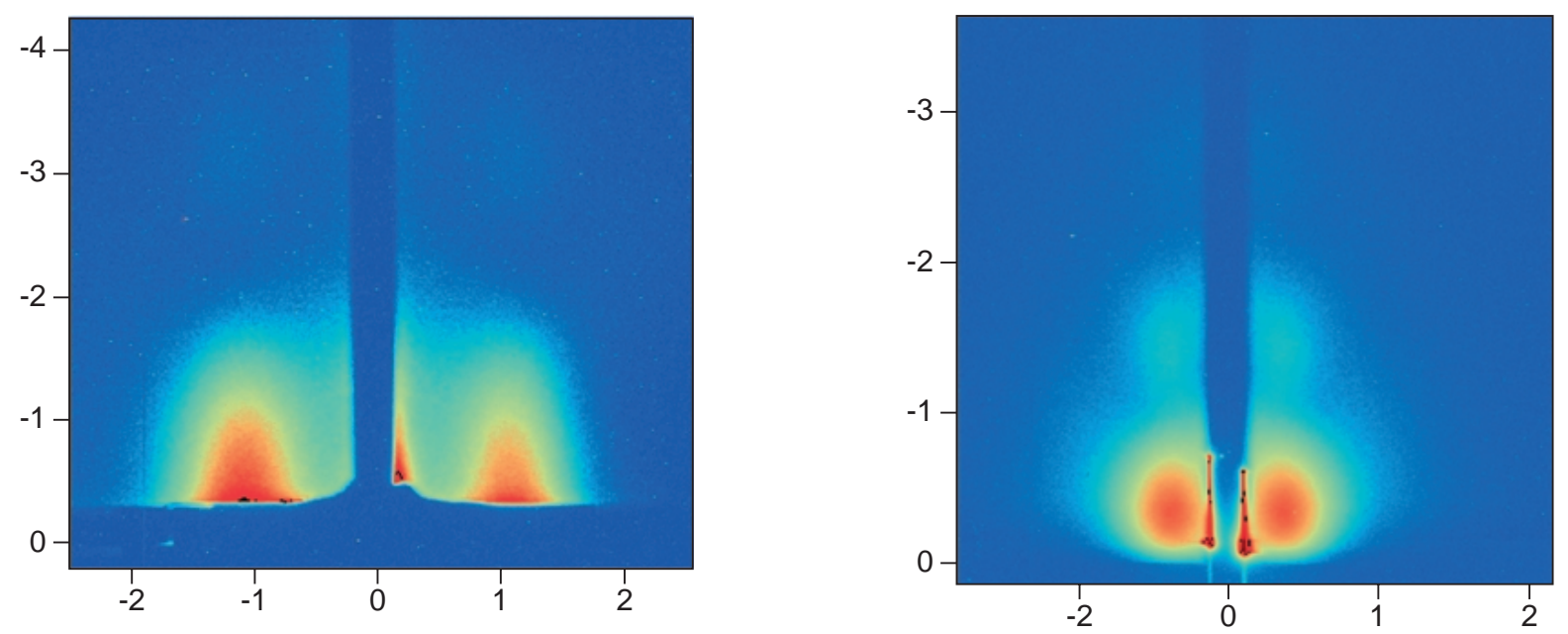

Figure 6

Evolution of the 2D GISAXS spectra with the size of the nanoclusters of PtRh formed on a Si amorphous oxide. The clusters are smaller, therefore the scattering is more diffuse and located at larger q values (left picture) than in the second case. Some roughness of the subtract can be seen along the beam stop. The second order is more visible in the right picture since the scattering is more concentrated. Courtesy of Pascal Andreazza.

developed by external laboratories in collaboration with the SOLEIL staff.

\section{TENDER AND SOFT X-RAYS METHODS}

\subsection{Absorption and Imaging with Tender X-rays}

Taking advantage of the brilliance of third generation machines, and of the fact that the quality of mirrors has considerably improved over the last few years, new beamlines can now be designed which offer at the same time a high flux and a very small spot size. The beamline LUCIA (Line for Ultimate Characterisation by Imaging and Absorption) is a "tender" $(0.8-8 \mathrm{keV}) \mathrm{X}$-ray microprobe with capabilities for chemical speciation by X-ray absorption spectroscopy ( $\mu \mathrm{XAS})$ and for elemental mapping by X-ray micro-fluorescence $(\mu \mathrm{XRF})$. It allows the possibility to measure heterogeneous samples at the micrometer scale and to combine these two element-specific techniques. A monochromatic beam of $\mu \mathrm{m}$ size is incident on a sample which is carried on a scanning $\mathrm{X}-\mathrm{Z}$ stage. $\mu \mathrm{XRF}$ shows the location of the elements, their relative abundances, and with which other elements they are associated. One can take advantage of the monochromatic beam which allows separating out different elements by their absorption edges. After mapping the fluorescence, interesting spots can be analysed by XAS to determine the speciation of the elements (local chemistry, quantitative determination of the local geometric structure around the absorbing atom) and how it depends on the different components. $\mu \mathrm{XRF}$ and $\mu \mathrm{XAS}$ can be combined with other microtechniques like Raman spectroscopy to give complementary information on the sample. The energy range offered by the beamline will correspond to the best performances of SOLEIL in terms of brilliance. It allows XAS experiments at the $\mathrm{K}$ edge of elements from $\mathrm{Na}$ to $\mathrm{Fe}$, L edges from $\mathrm{Ni}$ to $\mathrm{Gd}$, and $\mathrm{M}$ edges of rare earths and actinides. Thus, elements interesting in catalysis and in industrially important reactions can be probed. Developments of cells for in situ characterization using $\mu$ XAS have been recently reported offering new opportunities for the study of catalysts [55] with tender X-rays.

Installed at first on the Swiss Light Source located at the Paul Scherrer Institute (Switzerland) (SLS is a synchrotron light source running at $2.4 \mathrm{GeV}$ ), the LUCIA beamline will be transferred to SOLEIL by beginning 2008 . The beamline has been opened during summer 2004 to expert users, and scientists are now welcome to submit proposals to the PSI SLS Digital User Office (http://user.web.psi.ch/).

\subsubsection{Specification of the Beamline}

The source is a so-called APPLE-II type undulator with a magnetic period of $54 \mathrm{~mm}$. This device emits a light with fully tunable linear and circular polarization. The period length is such that no gap appears between the first and third harmonic in any polarization state. Such an undulator is highly advantageous for the analysis of oriented samples making use of polarized XAFS (P-XAFS). 
The beamline optics, comprising a set of premirrors and a fixed exit Kohzu two-crystal monochromator, delivers a harmonic free monochromatic beam tunable between 0.8 to $8 \mathrm{keV}$ thanks to five different crystal pairs, Beryl, KTP, $\mathrm{YB}_{66}, \mathrm{InSb}(111)$ and $\mathrm{Si}(111)$ fitting into water cooled holders. Thanks to the "gap scan" mode of the undulator, the beam at the exit of the monochromator shows a continuous variation allowing large energy scans for XAS experiments with a flux of about $2.10^{11}$ photons $/ \mathrm{sec}$. The resolving power is about 3000 .

Final focusing after the monochromator is by means of crossed mirrors in the Kirkpatrick-Baez configuration delivering a theoretical spot size of $1 * 2 \mu \mathrm{m}^{2}$ (ideal without slope errors). K-B devices have the major advantage to be achromatic, i.e. the focal length and the spot size do not change with energy. The typical working distance is $100 \mathrm{~mm}$. A motorized $(\mathrm{x}, \mathrm{y}, \mathrm{z})$-stage allows the very precise positioning and mapping of the sample. At low energy the samples have to be in a vacuum environment, but without special sample preparation. For XRF, a single-element silicon drift diode is used, with an energy resolution of about $130 \mathrm{eV}$, which can be approached close to the sample. A total-electron-yield detector and a Si-diode for transmission measurements are also available.

\subsubsection{Example of Scientific Results}

An example of the research accessible on LUCIA concerns the study of medieval glasses exposed to weathering since the XIV th century. It is developed by F. Farges (Université de Marne-la-Vallée). Glasses exposed to the outside suffered from corrosion (water, pollution, seasonal changes, etc). They show superficial crusts enriched in manganese. The experiment is described in Figure 7: the optical image select an interesting area, with unaltered glass and an altered part where complex compounds are formed. XRF mapping allows identifying the elements present in the different zones of the sample, and $\mu$ XRF gives the distribution of these elements. It was found that the distribution of $\mathrm{Na}$ and $\mathrm{Mn}$ are correlated, which infers the probable formation of a sodic birnessite which was not detected using conventional microscopic and diffraction studies. As confirmed by $\mu$ XANES experiments, the oxidation state of $\mathrm{Mn}$ is different in the different regions of the sample. The analysis of these results is in progress.

\subsection{Electron Spectroscopies and Time Dependence}

$\mathrm{X}$-rays are absorbed in matter and the energy of the X-rays is converted into the kinetic energy of photoelectrons, Auger electrons, secondary electrons and fluorescent X-rays. Here we focus essentially on "photon in-electron out" spectroscopies, such as core-level X-ray photoemission spectroscopy (XPS), valence-band UV photoemission spectroscopy (UPS) and near edge X-ray absorption fine structure spectroscopy (NEXAFS) measured in the electron yield (EY) mode.

The key "ingredient" of surface sensitivity is the inelastic mean free path $\Lambda: 95 \%$ of an elastic photoelectron peak comes from a surface layer of thickness $3 \Lambda$. $\Lambda$ is related to the kinetic energy $E_{K}$ of the emitted electron, and becomes very short (a few $\AA$ ) when $E_{K}$ is about $30-40 \mathrm{eV}$. Therefore, the energy tunability of the synchrotron radiation enables the measurement of photoemission spectra with a very good surface sensitivity. In surface experiments, X-ray absorption spectra cannot be measured by transmission: fortunately the EY resulting from the Auger decay of the core-holes created by the impinging photons can be monitored as a function of $h v$. When the depth from which the collected electrons originate is much smaller than the X-ray irradiated depth, then it can be shown [56] that the EY is proportional to the absorption coefficient. Various EY modes can be operated, the most reliable being the integrated measurement of a kinetic energy window centered on a selected Auger peak. In the case of an adsorbate (A) deposited at the surface of a substrate B, a very high adsorbate/substrate sensitivity can be obtained by measuring the Auger EY of A. The EY energy windows can also be adjusted to define an "effective sampling depth" $\Lambda_{\mathrm{e}} \cdot \Lambda_{\mathrm{e}}$ is large (typically $100 \AA$ ) when low $E_{K}$ (a few $\mathrm{eV}$ ) secondary electrons are collected (bulk sensitivity). Alternately, the NEXAFS spectra of surface states (with a high surface sensitivity) can be recorded by collecting secondary electrons of $E_{K}$ around $35 \mathrm{eV}$ [57] close to the minimum of the universal mean free path curve.

While XPS and UPS give information on the occupied electron levels, NEXAFS gives an "image" of virtual molecular orbitals (or of the unoccupied density of states for a solid) having a given symmetry dictated by the dipolar selection rules. All core-level spectroscopies (XPS and NEXAFS) are sensitive to the chemical environment of a given atom, and are widely used for chemical characterization. With respect to petrol chemistry, one can notice:

- that NEXAFS is able to distinguish multiple carboncarbon bonds from single bonds $[56,58]$ in organic compounds;

- and that it can be used to determine the oxidation degree (and spin state) of transition metals [59], which are used in catalysts.

Apart from its energy tunability, the big boon of synchrotron radiation is its polarization. As pointed out in Section 2.1.1, undulator sources are now able to provide linearly polarized light (vertical and horizontal) and elliptically polarized light. In surface chemistry, a big issue is the determination of the bonding geometry of a molecule on a surface. In that respect, UPS performed with linearly polarized light is capable of giving the parity (within a surface mirror plane) of the adsorbate molecular orbitals [60]; NEXAFS spectroscopy, using linearly polarized light, provides information on the bond orientation, and in some 

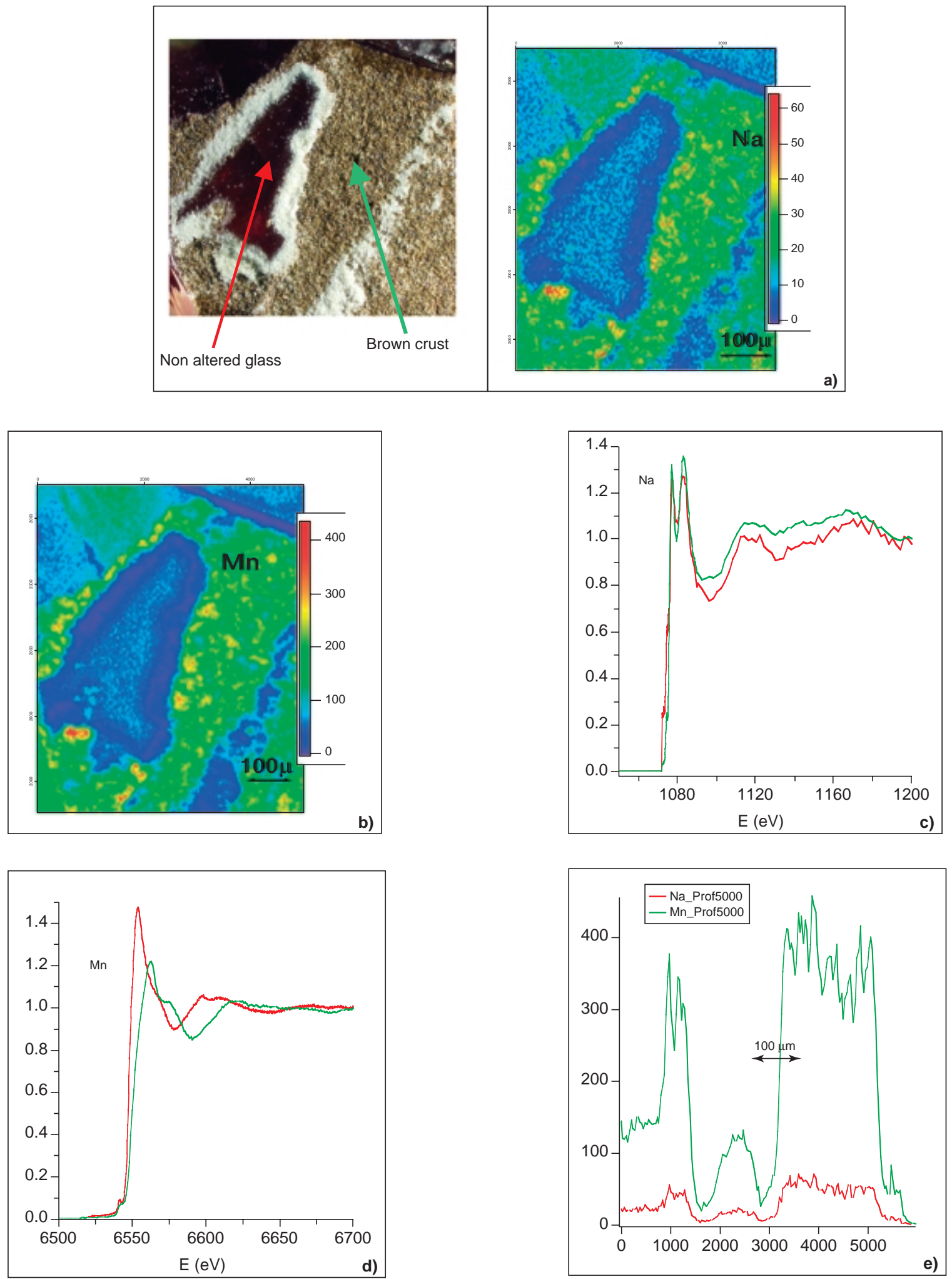

Figure 7

Images of the $\mathrm{Na}$ a) and $\mathrm{Mn}$ b) repartition obtained on medieval glass of the Tours' cathedral (XIVth century), XANES spectra at the Na c) and $\mathrm{Mn} \mathrm{K} \mathrm{d}$ ) edges for two spots: in the red non altered glass; in the brown crust formed during alteration. The line profiles e) of the abundance of these two elements evidence their correlation, and the XANES spectra show the different speciation of Mn in these two parts of the glass. Season impact or bacterial effect? 


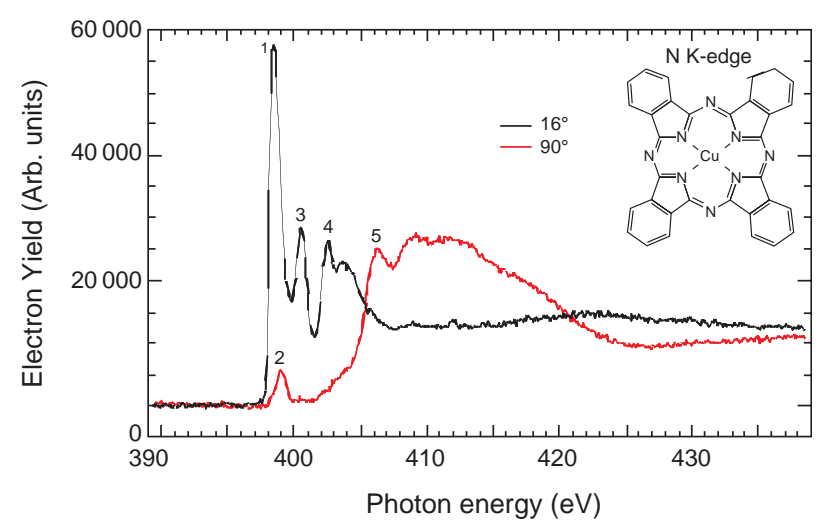

Figure 8

$\mathrm{N} 1 s$ NEXAFS spectra of a CuPc layer deposited on graphite, measured at two radiation incidence angle $\theta(\theta$ is also the angle between the surface normal and the polarization vector). At $\theta=16^{\circ}$ the transition from $1 s$ to the $\pi^{*}$ (transitions \# 1,3,4) system of the macrocycle is strongly enhanced. At $\theta=90^{\circ}$, one observes transitions to orbitals (\#2 and 5) contained in the molecular plane. Therefore the molecules lie flat on the graphite substrate. The data have been collected at beamline SB7, SuperACO.

instances, on the changes in bond-lengths [56]. An example of application of linearly polarized NEXAFS for the determination of molecular orientation is given in Figure 8: a $100 \AA$ thick copper phthalocyanine (CuPc) layer is deposited on a graphite substrate. The variation of the $\mathrm{N} 1 s$ absorption intensity as a function of radiation incidence shows that the $\mathrm{CuPc}$ molecular plane is parallel to the substrate surface. Generally speaking, the information on the electronic structure (both at energetic and spatial levels) provided by $\mathrm{UV} /$ soft $\mathrm{X}$ ray spectroscopies is highly valuable, as it compensates for the inability of X-ray surface crystallography to draw a picture of the surface, when adsorbates are made of low $\mathrm{Z}$ elements, and long range order may not be present.

The chemistry dedicated (or partly dedicated) beamlines of SOLEIL (TEMPO and MicroFocus) will cover a photon range bracketted between $50 \mathrm{eV}$ and $1500 \mathrm{eV}$. This energy range is particularly well suited for chemistry applications. On the one hand, UPS (valence band) photoemission is still feasible at $h v=50 \mathrm{eV}$. On the other hand, the whole range of $\mathrm{K}$ edges $(\mathrm{C}, \mathrm{O}, \mathrm{N}, \mathrm{F} 1 \mathrm{~s})$ of organic molecules, and the 4th period transition metal $\mathrm{L}(2 p)$ edges of metal-organic molecules is covered. Rare earth $\mathrm{M}_{4.5}$ edges are also accessible. With respect to the preceding installations at LURE, the SOLEIL beamlines will provide a general improvement in terms of (i) time and (ii) spatial resolution. The second issue is addressed in Section 2.3 devoted to spectromicroscopy. The first aspect is the hallmark of the high photon flux $\left(10^{12}\right.$ photon/s in a $4 * 50 \mu \mathrm{m}^{2}$ spot) TEMPO beamline. Real-time photoemission spectra will be recorded at a maximum speed of $20 \mathrm{~ms} / \mathrm{spectrum}$. Recently at LURE the valence band of a silicon surface continuously exposed to acrylonitrile has been measured at a speed of one spectrum every $7 \mathrm{~s}$ (Fig. 9) [61]. It has thus been possible to follow the quenching of the so-called surface state (characteristic of the clean surface reconstruction) and the growth of a molecular state. Note that the pressure was in the $10^{-9}$ mbar range. The maximum acceptable pressure in the present analysis chamber is about $10^{-6}$ mbar. In order to study "nonconventional" objects, on the surfaces of which important
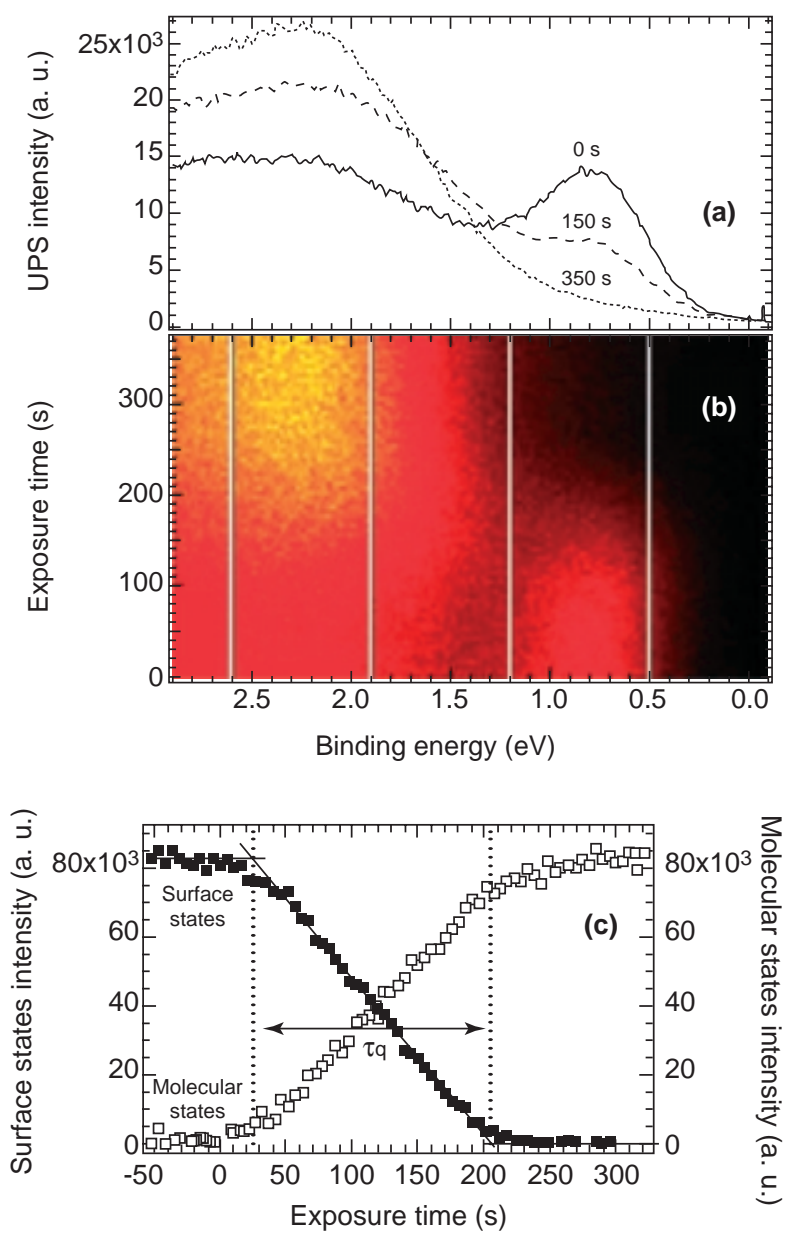

Figure 9

Real-time UPS (He I) of the $\mathrm{Si}(001)-2 \times 1$ surface exposed to acrylonitrile at $300 \mathrm{~K}$ under a pressure of $2.10^{-9} \mathrm{mbar}$. a) Photoemission intensity vs binding energy at times 0 (pristine surface), 150, and $350 \mathrm{~s}$ (saturated surface). The Fermi level is at $0 \mathrm{eV} . \mathrm{b}$ ) photoemission intensity (reflected in color scale from black (zero) to yellow $\left(10^{4}\right.$ counts) as a function of binding energy ( $\mathrm{x}$-axis) and exposure time (y-axis). Spectra are taken each $7 \mathrm{~s}$. Acrylonitrile is introduced at time zero. The white vertical lines delimit the integration windows of the surface states (centered at a binding energy of $0.85 \mathrm{eV}$ ) and of the molecular states (centered at a binding energy of $2.25 \mathrm{eV}$ ). The corresponding kinetics are reported in panel c). The data have been recorded at beamline SB7, SuperACO (see also Ref. [61]). 
(e.g. for atmospheric chemistry) chemical reactions take place, such as melting ice, or brine forming on salt crystals, an electron analyzer has been specially designed to work in the mbar range at the Advanced Light Source [62]. An equivalent apparatus might be built and installed on a branch of the TEMPO beamline.

In situ kinetic measurements are certainly superior to the classical trial and error method: in particular, given the high recording speed afforded by the high photon flux and the new ELETTRA-designed detector associated to the SCIENTA electron analyzer, we shall be able to detect transient species [63]. Beyond kinetic studies, we also want to examine various dynamical issues, using a laser as a pump and the $50 \mathrm{ps}$ wide X-ray pulse as a probe. Therefore, XPS/UPS and NEXAFS studies of electronically excited molecular states will be routinely feasible in the $p s$ regime.

Also extremely interesting is the possibility of studying a new kind of surface chemistry, by exciting the substrate electrons with a near IR laser. In fact in "classical" chemical reactions, heating the substrate enables the climbing of the vibrational ladder, within the molecular potential, until the bond breaks. In the case of interest, hot electrons (of a few eV) are produced in the substrate on a timescale much shorter than that of substrate heating. In these non-equilibrium conditions (the substrate phonons are not yet excited), the hot electrons do all the chemistry. It has been shown in recent fs resolved experiments that these electrons can displace an adsorbate $\left(\mathrm{O}_{2}\right.$ on $\mathrm{Pt}(111)$ ) from its rest position in a characteristic time of about $500 \mathrm{fs}$ [64]. It should be recalled here that the TEMPO beamline is designed to deal with fs sliced X-ray pulses [65] that will be produced in the near future at SOLEIL.

\subsection{Spectromicroscopy and X PEEM Imaging}

The high brilliance of third generation synchrotron radiation sources has opened the way to surface and interface imaging with resolution in the $10 \mathrm{~nm}$ ranges and with further instrument improvements in the $1 \mathrm{~nm}$ range [66]. Experimentally there are two different approaches. The first uses a well focused photon beam which is scanned across the sample's surface (SPEM: Scanning PhotoEmission Microscopy). The second employs parallel imaging techniques making use of appropriate electron optics (X-PEEM: X-ray PhotoEmission Electron Microscopy).

\subsubsection{The Spectromiscroscopy}

$\mathrm{X}$-PEEM spectromicroscopy is a derivative of the classical PEEM. If photon energy just above the photothreshold is used, the total photoelectron yield (TEY) is mainly determined by the differences in the work function $\phi$ of the sample. The local variations of $\phi$ result in images with high contrast. This UV-PEEM mode of operation is ideally suited to study surface chemical reactions in real time [67]. With the advent of high brilliance synchrotron radiation from third generation storage rings, a wide and tuneable energy range of photons of the illuminating beam has become available. This allows to access well established techniques like Ultraviolet Photoemission Spectroscopy (UPS), X-ray

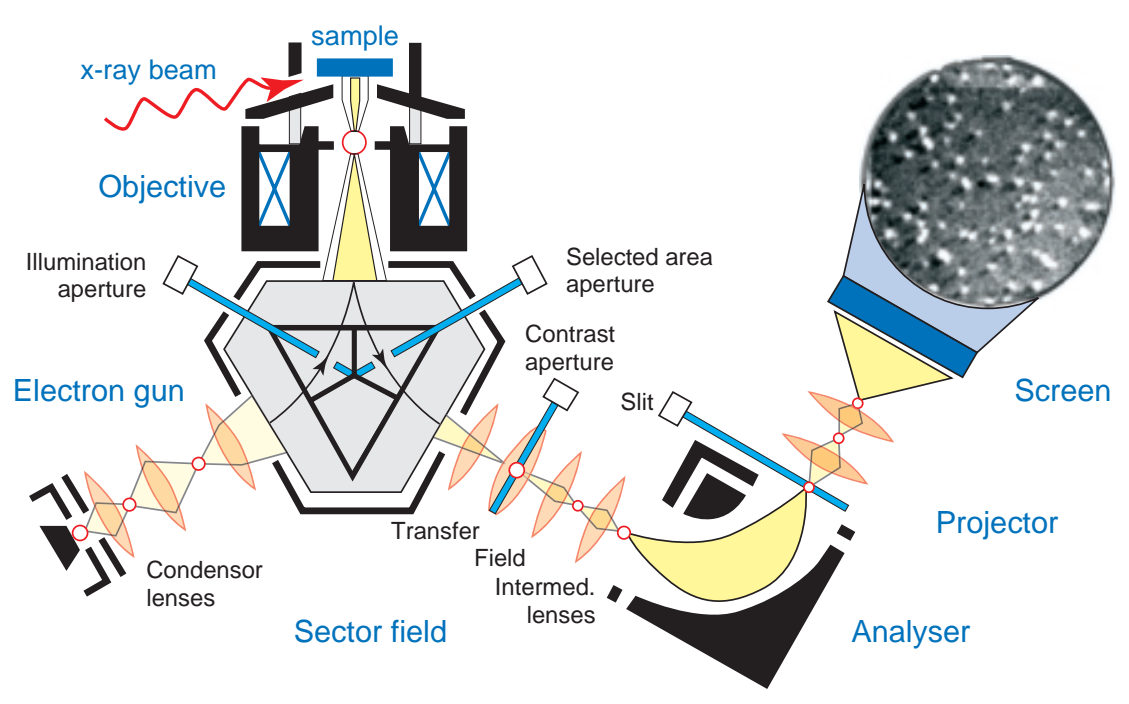

Figure 10

Schematic sketch of the X-PEEM microscope. The sample is illuminated using a monochromatic X-ray beam. The Electron yield is collected via an immersion lens, magnified and projected using an electron microscopy column. The image obtained on the detector, represents a magnified image of the observed area on the sample, generated using the secondary or primary photoelectrons. Note that the microscope can also operate using an electron gun, which enable Mirror Electron Microscopy (MEM) and Low Energy Electron Microscopy (LEEM). (Courtesy of A. Locatelli, Trieste - Italy). 
Photoemission Spectroscopy (XPS), X-ray absorption spectroscopy (XAS) and Near Edge X-ray Absorption Spectroscopy (NEXAFS) at the nanoscopic level, and thus leading to element selective imaging (see Fig. 10). Moreover, information on the spatial distribution of the electronic structure, chemical composition and on the local chemical bonding of atoms and molecules at the surface can be obtained. Dedicated beamlines with high brilliance, variable photon polarization (circular as well as linear) and a broad energy range have become recently available at several facilities (Elettra, ESRF, ALS, BESSY II, etc.). This opens a wide research area for the X-PEEM [68] including surface magnetism, surface and interfaces, surface chemistry, tribology, etc.

The study of surface chemical reaction has constituted for a long time one of the favorite domain of application for the PEEM microscopy [69, 70]. Chemical reactions, which show complex phenomena of pattern formation, have recently moved into the focus of the research interest. Among others, catalytic reactions on single crystal surfaces play a particular role not only because of their practical importance, but also due to the relative simplicity of their mechanism. Moreover, their intrinsically two-dimensional geometry allows applying various observation methods, ranging from optical and electron microscopy to scanning tunnelling microscopy, and hence to directly study the reaction process down to the atomic resolution. The studies of the reaction fronts formed during the chemical reaction on single crystal surface have been considered as a first step in the comprehension and in the formulation of realistic models [71, 72]. As discussed below, an impressive variety of different chemical wave patterns has been found in recent years [73, 74]. Moreover the temporal resolution of PEEM (few $\mathrm{ms}$ ) is always sufficient for the observed dynamical process.

\subsubsection{Chemical Waves and Surface Chemical Reaction}

The CO oxidation reaction on $\operatorname{Pt}(110)$ is one of the most thoroughly investigated systems as it is believed to be the first step to the comprehension of the surface chemical reactions. Molecular beam investigations have shown that this reaction proceeds via the Langmut-Hinshelwood mechanism (i.e., $\mathrm{CO}$ and oxygen have to be adsorbed before the $\mathrm{CO}_{2}$ formation can take place). PEEM observation under reaction conditions shows a new class of pattern (chemical waves) attributed to subsurface oxygen [73]. These new class of waves have unusual properties. Instead of annihilation, typical for previously observed oxygen waves in the same reaction, their frontal collisions result in reflections or fusion of two fragments and formation of a single traveling fragment. PEEM observations on island conversion process have been used to modelize this kind of reaction. However, mathematical model have been developed only for such chemically very simple system. The main obstacle in the formulation of realistic reaction-diffusion models for more complex reactions like $\mathrm{NO}+\mathrm{H}_{2}$ on $\mathrm{Pt}$ and $\mathrm{Rh}$ [75] surfaces is the limited amount of information about the lateral distribution of adsorbate species on the surface. PEEM imaging since it is based upon work function contrast cannot provide, or very indirectly, information about the chemical identity of the absorbate species. The combination of spectromicroscopy imaging and element-specific spectroscopic techniques using synchrotron radiation, allows to access to relevant parameters such as the concentration profiles of the surface species for traveling pulse.
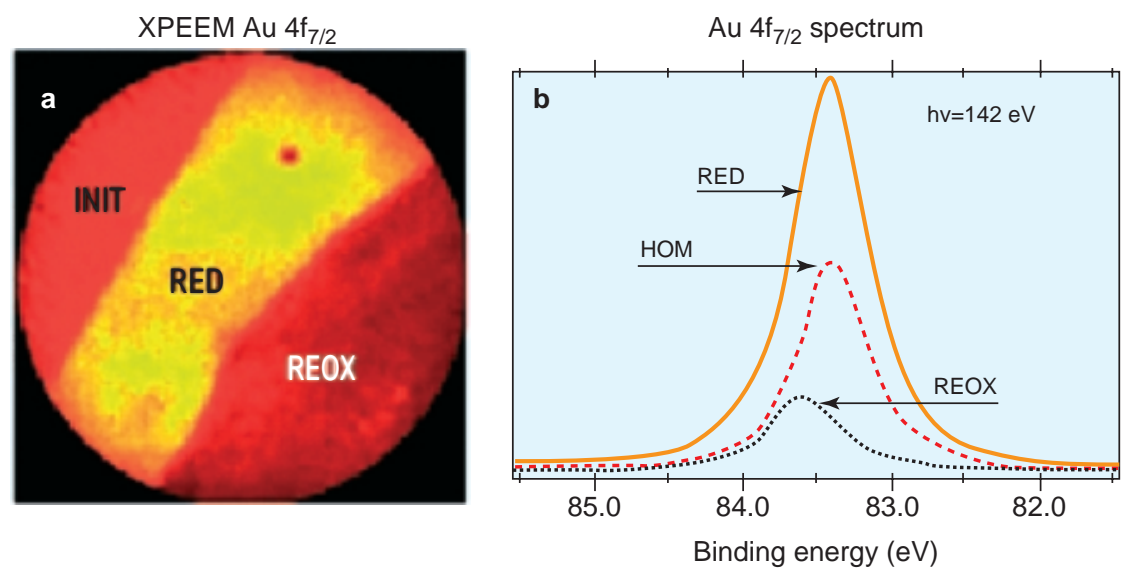

Figure 11

a) X-PEEM image illustrating the evolution of the reaction toward a stationary state. The developed re-oxidation fronts (REOX) have triggered the redistribution of $\mathrm{Au}$, which accumulates on the already reduced surface (RED). Reaction parameters: $\mathrm{p}\left[\mathrm{O}_{2}\right]=4.4 .10^{-7} \mathrm{mbar}$, $\mathrm{P}[\mathrm{H} 2]=3 \cdot 8 \cdot 10^{-7} \mathrm{mbar}, \mathrm{T}=620 \mathrm{~K}$. Field of view $5 \mu \mathrm{m}$. b) Local XPS Auf $\mathrm{f}_{7 / 2}$ spectra taken in the three different regions shown in the X-PEEM image. The full reduction of the surface leads to the homogenisation of the Au coverage [79, 80]. 
The first combination of microscopic and spectroscopic measurements to study the chemical reaction has been recently reported [75]. The experiments have been realized by use of scanning photoelectron microscopy (SPEM) with synchrotron radiation focused to nanoscale dimensions by Fresnel zone plates in order to modelize the $\mathrm{Rh}(110) / \mathrm{NO}$ $+\mathrm{H}_{2}$ chemical reaction. Using O1s, N1s and $\mathrm{Rh}_{3} \mathrm{~d}_{5 / 2}$ core level photoemission, bidimensional maps of the surface composition during the reaction condition have been recorded. From these images, the concentration profile for the two relevant species ( $\mathrm{O}$ and $\mathrm{N})$ has been deduced and compared to a mathematical calculation which enables to deduce a global model for the excitation mechanism of the traveling pulse.

In catalytic and surface reactions, adsorbed atoms and molecules not only act as reactant but also modify the structure and the electronic state of the surface under the working conditions and hence the reaction kinetics and mechanisms may be largely affected [76-78]. Therefore, chemically and structurally sensitive techniques with high lateral, spectral and time resolution are required in order to fully investigate such complex surface reaction. The contribution of X-PEEM microscopy is undeniable as it has been clearly demonstrated recently in the study of the water formation reaction on a Au-modified $\mathrm{Rh}(110)$ surface [79, 80]. It was found that oxidation front triggers redistribution of the initially uniform Au adlayer. The propagating oxidation fronts destroy the homogeneity of the interface and re-organize the interface in two separated phases (see Fig. 11), which are energetically more favorable than a single homogeneous $\mathrm{O}+\mathrm{Au}$ coadsorbed phase.

\subsubsection{NEXAFS and X-Ray Linear Dichroism Microscopy}

One interesting direction to prospect in the future is the combination of NEXAFS spectroscopy and X-PEEM. As a matter of fact, the NEXAFS spectroscopy as mentioned in Section 2.2 has become nowadays a widely used technique for study of the electronic and geometrical structure of organic materials and low-Z molecules bonded to surfaces. The power of NEXAFS spectroscopy lies in its ability to detect the presence of specific bond in molecules and polymers $(\mathrm{C}-\mathrm{C}, \mathrm{C}=\mathrm{C}, \mathrm{C}=\mathrm{O}$, etc.) and its capability to derive the precise orientation of molecules on surfaces. Orientation information is derived from the linear dichroism in X-ray absorption i.e. the strong dependence of the resonant photoexcitation process on the relative orientation of light polarization and the molecular orbital of interest. The NEXAFS approach can be extended to spectromicroscopy for imaging chemical molecules domains on surfaces. Similarly to what has been recently demonstrated for the magnetic imaging [81, 82], the use of the linear dichroism with the chemical bond sensitivity makes it possible to image a domains or a group of molecules that differs from the adjacent species only in the molecular orientation. Until now, such X-ray linear dichroism microscopy had been almost exclusively applied to image the orientation of specific chemical bonds in polymers. However, recently, some promising results have been obtained in the study of the adsorption geometry of organic adsorbate on metal [83, 84]. Actually this domain remains unexploited, but the generalization of X-PEEM spectromicroscopy on third generation synchrotron laboratory will ensure an extensive use of this capability as is it the case actually for the NEXAFS spectroscopy.

\subsubsection{The Microfocus beamline at SOLEIL [85]}

The purpose of the X-PEEM branch of the MicroFocus beamline at SOLEIL is first and foremost to deliver the highest flux possible within a small focused beam over the 50 to $1500 \mathrm{eV}$ spectral ranges. The flux at the sample position will be above $10^{13}$ ph.s. ${ }^{-1}$ over the optimized energy range. The wide energy range will enable UPS photoemission, XPS photoemission, NEXAFS at the K edges of light elements (C, O, N 1s...) as well as XAS spectroscopy at the $\mathrm{L}$ edges of transition metals and at the $\mathrm{M}$ edges of the rare earths.

In brief, the beamline will involve a medium section tunable undulator and a VLS (variable line space) grating monochromator designed to provide a resolving power of at least 5000 at full throughput. Kirkpatrick-Baez (KB) bendable mirrors will be available to focus the beam according to requirements of instrumental constraints which dictate the need for a very well focused beam in both vertical and horizontal planes. The KB mirrors will provide $\mathrm{a} \sim 2 \mu \mathrm{m}$ x $10 \mu \mathrm{m}$ beamspot with no extra loss in flux other than from reflections. This will provide optimum performance for high resolution X-PEEM experiments. The X-PEEM instrument is based on a commercial LEEM/PEEM microscope (Elmitec Gmbh.) initially designed by Pr E. Bauer. This instrument has the advantage that it can be used in both LEEM (Structural and morphological microscopy) and XPEEM modes. It also permits the best resolution achieved to date $(8 \mathrm{~nm}$ in PEEM mode and $22 \mathrm{~nm}$ in X-PEEM using core level electrons). A certain number of important developments will be also performed in order to get a high level instrument:

- A key limitation to the performance of electron-optical Xray microscopes is the severe chromatic and spherical aberrations of the immersion lens used. This problem constrains the X-PEEM microscope to a fairly small transmission in an attempt to offset these problems. Rempfer's group [86] has proposed a solution to this problem, by designing and testing an electron mirror, which has spherical and chromatic aberrations of similar magnitude to the objective lens, but opposite in sign. When used in combination with a properly designed objective lens, the aberration can be highly reduced. Therefore both transmission and resolution will be 
increased (Expected improvements: factor 5 in term of spatial resolution and a factor 600 in term of transmission). Two major projects using correcting mirrors are presently under construction: PEEM3 at ALS and SMART project at BESSYII.

- The incorporation of an energy filter in the X-PEEM microscope with an energy resolution better than $150 \mathrm{meV}$ for core level and valence band photoemission microscopy. The energy filter is not only necessary for imaging with primary photoelectrons but also useful for secondary electron imaging. It allows to select a narrow energy window around the maximum of the secondary electron energy distribution and, thus, to improve the spatial resolution without unacceptable loss of transmission.

All these developments will be made on the basis of the commercial $90^{\circ}$ LEEM/PEEM with the collaboration of Pr. E. Bauer (Arizona State University) and the microscopy group of Elettra-Italy (M. Kiskinova and A. Locatelli). The instrument will be first installed on the Nanospectroscopy beamline at Elettra synchrotron ring storage prior to its final relocation at SOLEIL, $c a .2007$.

\section{INFRARED METHODS}

For the past decade, synchrotron radiation has impacted the field of infrared spectroscopy and micro-spectroscopy in various disciplines including Physics and Chemistry, Earth and Space Science, Biology, Soft Matter, etc. After the first demonstration of the brilliance advantage of the synchrotron infrared source, significant effort was devoted to understanding and optimizing the source qualities in the infrared region, comprising both the so-called mid infrared $(\sim 2$ to $\sim 20 \mu \mathrm{m})$ and far infrared ( 20 to $\sim 1000 \mu \mathrm{m})$ regions. The earliest efforts to develop the synchrotron infrared source were motivated by the need for a bright far infrared source in low throughput experimental methods such as grazing incidence spectroscopy from surfaces [87]. Though it was understood that the brilliance advantage of the synchrotron source extended up into mid-IR, an actual demonstration of its use for spectro-microscopy did not occur until Hemley and co-workers [88] developed a custom instrument to focus light through a high pressure diamond anvil cell at the National Synchrotron Light Source (NSLS) of Brookhaven National Laboratory. The first microspectroscopy experiments that allowed a direct comparison with a thermal source took place in 1993, when a commercial Spectra Tech Irus infrared microscope was installed at U2B; a dedicated mid-IR beamline at the NSLS $[89,90]$. Since that time, farIR and mid-IR spectroscopy and microspectroscopy has expanded to synchrotron facilities throughout the world. Principal motivation for synchrotron-based IR spectroscopy and microspectroscopy are: the superior advantage in flux (wavelength> 100 microns) for the far-IR and tremendous superiority in brilliance, both in the far-IR and mid-IR region. In far-IR spectroscopy, this is of paramount importance in studying the adsorbate-substrate bonding, the optical properties of super-, and semi- conductors, phonon modes of substrates, collective motions of molecules. In microspectroscopy, the synchrotron source brilliance is essential for achieving significantly greater lateral resolution (typically at the diffraction limit) in combination with superior signal to noise and without resorting to prohibitively long acquisition times.
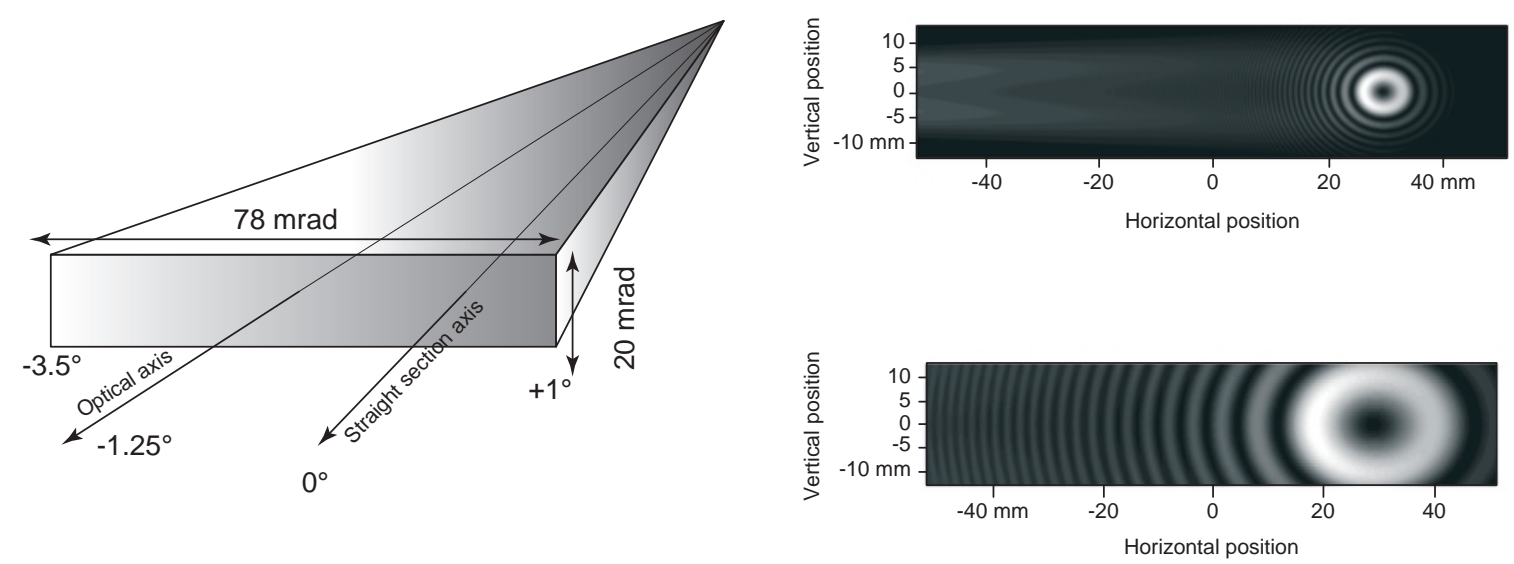

Figure 12

Left: Collection geometry: the dipole vessel has been modified in order to collect photons emitted in a 78 mrad horizontal x 20 mrad vertical opening angles. The emission of the edge radiation is centered on the axis of the straight section, while the constant field emission occurs at negative values of angles. Upper Right: emission profile for a wavelength of 10 microns (mid-IR); Lower right: emission profile for a wavelength of 100 microns (far-IR). 


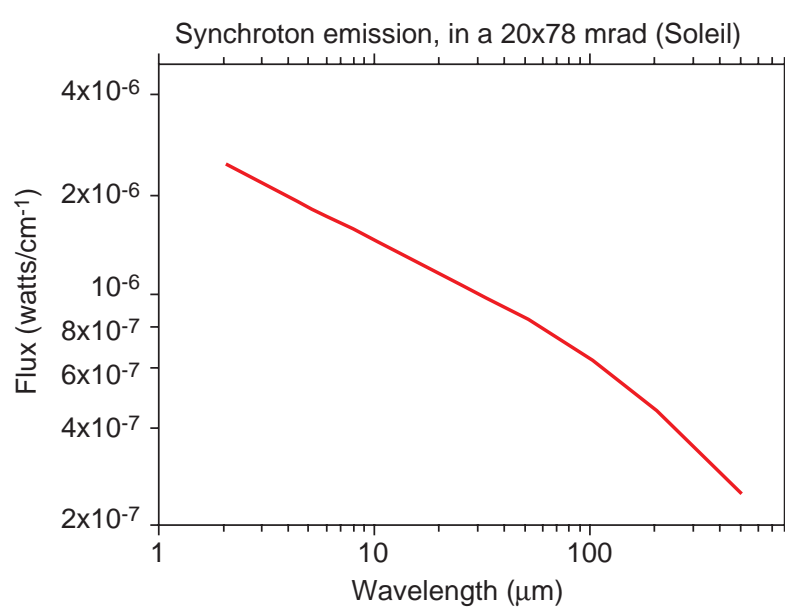

Figure 13

Total flux emitted at SOLEIL, collecting both the edge radiation, and the constant field emission.

Accordingly, a special care has been initiated at SOLEIL, to understand the physics of infrared emission, and to optimise the photons collection and propagation to spectrometers through sophisticated simulation software.

There are two main sources of infrared radiation: Infrared is generated by electrons traveling at relativistic velocities, either inside a curved path through a constant magnetic field (bending magnet radiation [91]) or by longitudinal acceleration or deceleration when leaving or entering a magnetic section (edge radiation) [92, 93]. At SOLEIL, we have designed a modified dipole chamber which allows the two sources to be collected simultaneously. The collection geometry, and the calculated wavefront, for two characteristic wavelengths, are reported on Figure 12. Calculations have been performed using the software SRW developed by Oleg Chubar and Pascal Elleaume [94] and, later on, upgraded for propagating the wavefront along all optical elements, by O. Chubar. Figure 13 shows the emitted photon flux, expressed in Watts $/ \mathrm{cm}^{-1}$, a unit more familiar to spectroscopists.

The synchrotron radiation can be used in pump-probe studies of dynamics, as exemplified in references [95, 96], and is particularly well suited for experiments where multiple and widely varying photon energies or wavelengths are required. An example is the combination of X-ray (fluorescence or absorption) and IR microscopic analysis on the same sample $[97,98]$ which represents an activity of growing interest in the synchrotron radiation community.

Two infrared beamlines are under construction at SOLEIL. The two infrared ports will be used in one hand, for far-IR spectroscopy, with medium to very high resolution (beamline AILES), and on the other hand for infrared microspectroscopy (beamline SMIS).

\subsection{Spectroscopy (AILES)}

\subsubsection{Experimental Conditions for Heterogeneous Catalysis in situ Measurements}

In relation to their high surface area, zeolites and powdered oxides play a central role in heterogeneous catalysis. Those material surfaces present a high reactivity but often need a detailed characterization of their adsorbing sites. The characterization of their surface, however, should be preceded by a thermal treatment able to remove all the molecules pre-adsorbed on the catalytic active centres coming from the ambient atmosphere (activation process). This process is a requisite for the study of well-defined systems [99]. After the activation, measurements can be performed, in situ, either on the "as activated" sample (i.e. under vacuum conditions) or after having dosed a well defined amount of high purity gas on the sample. The comparison between the data collected before and after the adsorption of a specific molecule allows extracting important information concerning the interaction process. The far infrared region being the energy range of the physical adsorption, it allows to probe the interaction involved at the active site. The typical molecules employed in these studies are either very simple molecules such as $\mathrm{CO}, \mathrm{N}_{2}, \mathrm{H}_{2} \mathrm{O}, \mathrm{NH}_{3}$, $\mathrm{CO}_{2}$, etc., or those involved in the chemical reactions occurring on the catalyst $\mathrm{NO}, \mathrm{O}_{2}, \mathrm{HCl}, \mathrm{C}_{2} \mathrm{H}_{4}$, etc.

\subsubsection{Rotational Spectroscopy of $\mathrm{NH}_{3}$ Molecules Hosted Inside the $\mathrm{Cu}^{+}-\mathrm{Y}$ Zeolite}

Figure 14 reports the far-IR spectra collected at room temperature at LURE Super-ACO (SIRLOIN beamline) on the $\mathrm{NH}_{3} / \mathrm{Cu}^{+}-\mathrm{Y}$ system. Notice the extended range permitted by the use of the brilliant far infrared synchrotron source. Curve 1 reports the zeolite background before interaction with $\mathrm{NH}_{3}$. Upon dosing ammonia (curve 2) the transmittance is strongly reduced and the pure rotational spectrum of $\mathrm{NH}_{3}$ trapped inside the $\mathrm{Cu}^{+}-\mathrm{Y}$ cages is observed. The same $\mathrm{NH}_{3}$ equilibrium pressure dosed on the cell without the zeolite pellet results in a negligible absorption, due to the too low optical path. The presence of the $\mathrm{Cu}^{+}-\mathrm{Y}$ sample causes the condensation of $\mathrm{NH}_{3}$ molecules in the zeolite cavities, making possible the observation of the rotational spectrum. Curve 3 reports the far-IR spectrum obtained upon activation at room temperature (aimed to remove only $\mathrm{NH}_{3}$ molecules not specifically interacting with $\mathrm{Cu}^{+}$sites), showing the hindered rotational spectrum of $\mathrm{NH}_{3}$ molecules of the $\mathrm{Cu}^{+}\left(\mathrm{NH}_{3}\right)$ complexes. This observation allows a quantitative characterisation of the sites available for the $\mathrm{NH}_{3}$ molecules and supports the microcalorimetric measurements showing that the interaction of $\mathrm{NH}_{3}$ molecules with $\mathrm{Cu}^{+}$ions hosted in zeolitic matrix is only partially reversible at room temperature [100]. 
Other far-IR experiments have shown the Na-C stretching mode at $140 \mathrm{~cm}^{-1}$ of the $\mathrm{Na}^{+}(\mathrm{CO})$ adduct formed at $80 \mathrm{~K}$ inside $\mathrm{Na}^{+}-\mathrm{ZSM}-5$ zeolite [101] and the perturbation of the $50 \mathrm{~cm}^{-1}$ phonons of the $\mathrm{Na}^{+}-\mathrm{ZSM}-5$ framework upon adsorption at room temperature of $\mathrm{CO}_{2}[102]$.

\subsubsection{Surface Studies}

Surface Science has proposed, for several years, models for adsorbate-substrate interaction, as a mimic of catalytic reaction, using diatomic molecules on well known surfaces. On the one hand, copper surfaces have been widely used as models for catalysis, and a huge amount of articles were dedicated to the $\mathrm{CO} / \mathrm{Cu}$ interaction. On the other hand, $\mathrm{NO}$ was also investigated on various surface orientations $(\mathrm{Cu}(100), \mathrm{Cu}(111)$ and $\mathrm{Cu}(110))$.

It was observed that $\mathrm{NO}$ was linearly adsorbed on $\mathrm{Cu}(111)$, with its axis perpendicular to the surface plane, in the first stages of deposition, but, close to monolayer completion, the NO signal (as seen by mid-infrared spectroscopy) disappears. It was then concluded that lateral interactions between adjacent NO molecules was strong enough to induce a complete desorption from the surface.

Using synchrotron radiation, the study was focused on the direct adsorbate-substrate bond (intermolecular bonding), and found evidence for the presence of $\mathrm{N}_{2} \mathrm{O}$ molecules as illustrated on Figure 15 [103]. Chemical reaction between ad-molecules has thus been induced by lateral interaction at the surface. This full understanding could not be achieved without use of high flux and high brilliance synchrotron radiation source.

\subsection{Microscopy and Imaging (SMIS)}

Spatially resolved infrared micro-spectroscopy produces a 2-dimensional array of spectra from which a chemical image, or "map", can be generated. Spectroscopic imaging provides diagnostic information in a visual form, a prospect appealing to physicians and biologists. Imaging methods can provide potentially more straightforward information to nonspecialists than their non-imaging counterparts. However, the analysis and diagnostic potential of IR imaging strongly depends on the quality of the spectra acquired. Clearly, the synchrotron source contributes significantly to these improvements.

Though most IR microscopy imaging makes use of the rich and unique absorption features found in the mid-IR for chemical identification, there is an increasing interest in extending the spectral range to lower frequencies, motivated in part by developments in coherent $\mathrm{THz}$ spectroscopy and imaging [104], but also in response to the needs of the space sciences community for the identification of complex minerals found in interplanetary dust particles [105]. The broad spectral coverage and high brilliance of synchrotron radiation reaches well into the far infrared, to below $1 \mathrm{THz}$ [106].

Illustrations of capabilities in microanalysis of Geologicalrelevant inclusions are presented in the article of $\mathrm{N}$. Guihaumou et al., in this issue.

\subsection{Summary}

SOLEIL will offer many opportunities for infrared spectroscopy and microscopy, using the brilliance advantage

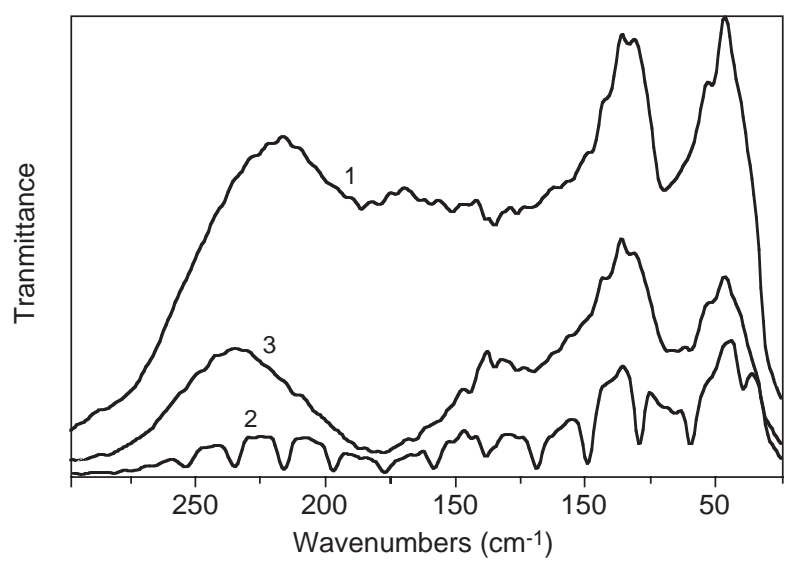

Figure 14

Room temperature Far-IR spectra of $\mathrm{NH}_{3}$ dosed on $\mathrm{Cu}^{+}-\mathrm{Y}$ zeolite. Curve 1: sample background before interaction with of $\mathrm{NH}_{3}$. Curve 2: $\mathrm{Cu}^{+}-\mathrm{Y}$ zeolite in presence of 20 Torr of $\mathrm{NH}_{3}$. Curve 3: after subsequent activation at RT.

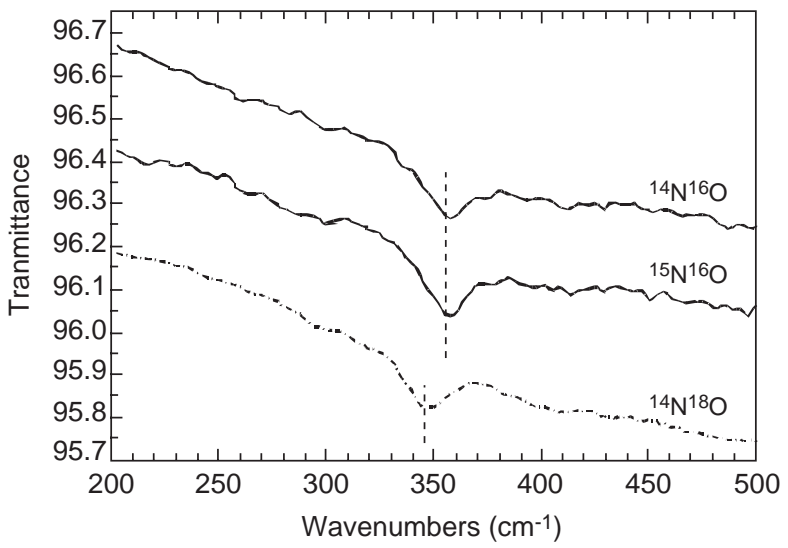

Figure 15

Frequency dependence of the low frequency mode, for $5 \mathrm{~L}$ exposure of $\mathrm{NO}$, on $\mathrm{Cu}(111)$, at $\mathrm{T}=90 \mathrm{~K}$. The low frequency mode is downward shifted upon oxygen labelling (3\%). This has been interpreted as a $\mathrm{Cu}-\mathrm{ON}_{2}$ peak, as the $\mathrm{Cu}-\mathrm{O}$ peak would have shifted by $6 \%$. 
brought about by the synchrotron source. An infrared "village" will allow a synergy between specialists, and in particular, for the studies related to Earth Science, organic compounds contained in small inclusions, or adsorbed at surfaces of the rocks. It is clear that catalysis will also benefit a lot from the infrared infrastructure at SOLEIL.

\section{CONCLUSION}

An overview of the potentialities offered by the different SOLEIL beamlines to study materials, with the emphasis on catalytic materials, has been presented in this paper. These beamlines should fulfil the needs of the user's community for which the characterization of a catalytic system requires complementary techniques. X-ray absorption, X-ray diffraction and X-ray scattering techniques in the hard X-ray range will be mainly concerned by the structural and electronic study of the catalyst itself (metallic nanoparticles, supported catalysts, etc.), its genesis, its activation under in situ treatments, and, its reactivity by looking at the catalyst changes. These techniques are now well established as standard tools for catalysis and should greatly benefit of the high brilliance of SOLEIL with an access to time resolved information at different time scale (from the $\mathrm{ms}$ to $\mathrm{s}$ ) and to a lower detection limit of the active element in the catalyst. Surface characterizations of catalyst at each step of its "life" (genesis, activation and reaction) will be accessible through the grazing incidence techniques allowing to better describe not only the surface itself but also the interface between the catalyst and the reaction product. The tender and soft X-rays methods will be more concerned by the electronic structure of the catalyst (e.g. oxidation state of metallic particles) and the study of interfaces either between catalyst and substrate for supported catalyst or between the catalyst and the reactive adsorbed species. In particular the use of the linear polarization of synchrotron radiation will allow to understand the adsorption of light molecules ( $\mathrm{CO}, \mathrm{NO}, \mathrm{O}_{2}$, etc.) on the catalysts. The emergence of spatially resolved methods using either X-ray absorption and fluorescence techniques or photoemission electron microscopy should be a promising tool for characterizing the $\mu$-meter heterogeneity of catalysts and surface chemical reaction at the nanometer scale, respectively. For both imaging methods, the complementary use of the linear polarization of the synchrotron radiation will be also profitable for determining the orientation of adsorbates on heterogeneous surface. Finally the access to infrared methods which give relevant information on the vibrational characteristics of important adsorbed species in catalysis, such as $\mathrm{CO}$, NO, etc., will complete the panel of operando techniques for the study of catalysts.

As evidenced through this review, a collaboration between the user's community and the scientists responsible of the concerned beamlines is mandatory and appears as a prerequisite for the extensive and succesful use of SOLEIL for catalysis studies. This should be materialized along different ways: the definition and participation to the development of in situ cells within structured programs such as those meet in some other synchrotron radiation laboratories (see for example http://www.bnl.gov/chemistry/ research_programs.asp), the financial and/or manpower investment to push one of the specifications of the beamline towards the study of catalyst and so on, etc. It should be mentioned here that the already impressive number of beamlines available for the study of catalytic objects will be reinforced by support laboratories. Beside the user's opened laboratory of each beamline for sample conditioning for the synchrotron radiation measurement, the chemistry and surface laboratories will operate research facilities such as ovens, ultracentrifuge set-up, glove boxes, etc. UV-Vis and Raman spectrometers, Differential Scanning Calorimeter, etc. and Scanning Tunnelling Microscope, etc. These laboratories will be available to the SOLEIL researchers but also to users within active collaboration.

Finally, SOLEIL is willing to facilitate the access of industrials and applied research groups to the beamlines, either through the usual channel of programme committees for cooperative research with no publication restriction or through dedicated beamtime for proprietary research. In the latter case rapid access will be provided by a policy of shift reservation, a support for data collection and analysis from members of the beamline team can be envisaged if needed. In case of a very heavy demand for specific techniques, dedicated beamlines with specialized teams could be built with a proper funding scheme.

\section{ACKNOWLEDGEMENTS}

Xavier Carrier (Laboratoire de Réactivité de Surface, Paris VI), François Farges (Laboratoire des Géomatériaux, Université de Marne-la-Vallée), Marie-Claire Saint-Lager (Laboratoire de Cristallographie, Grenoble) are gratefully acknowledged for providing us with unpublished results.

\section{REFERENCES}

1 Belin, S., Briois, V., Traverse, A., Idir, M., Moreno, T. and Ribbens, M. (2005) SAMBA: A New Beamline at SOLEIL for X-Ray Absorption Spectroscopy in the 4-40 keV Energy Range. Physica Scripta T115, 980-983.

2 Proux, O., Biquard, X., Lahera, E., Menthonnex, J.J., Prat, A., Ulrich, O., Soldo, Y., Trévisson, P., Kapoujvan, G., Perroux, G., Taunier, P., Grand, D., Jeantet, P., Deleglise, M., Roux, J.P. and Hazemann, J.L. (2005) FAME: A New Beamline for X-ray Absorption Investigations of VeryDiluted Systems of Environmental, Material and Biological Interests. Physica Scripta T115, 970-973.

3 Gailhanou, M., Dubuisson, J.M., Ribbens, M., Roussier, L., Bétaille, D., Créoff, C., Lemonnier, M., Denoyer, J., Bouillot, D., Jucha, A., Lena, A., Idir, M., Bessière, M., 
Thiaudière, D., Hennet, L., Landron C. and Coutures, J.P. (2001). H10: A Materials and High Temperature Beamline at DCI/LURE. NIM A, 467-468, 745-747.

4 Frahm, R., Richwin, M. and Lützenkirchen-Hecht, D. (2005) Time-Resolved Extended X-ray Absorption Spectroscopy using Continuous Sequential Energy Scanning on a SubSecond Scale. Physica Scripta T115, 974-976.

5 Schroeder, S.L.M., Moggridge, G.D., Lambert, R.M. and Rayment, T. (1997). Thermal Dehydration of Hydrous Chromium Hydroxide Gel: In Situ Studies by Total ElectronYield XAS. J. Phys. IV, 7, C2-923.

6 Chao, K.J. and Wei, A.C. (2001) Characterization of Heterogeneous Catalysts by X-ray Absorption Spectrsocopy. J. Elec. Spec. and Rel. Phen., 119, 175-184; Russel A.E. and Rose, A. (2004) X ray Absorption Spectroscopy of Low Temperature Fuel Cell Catalysts. Chem. Rev., 104, 46134636; Bazin, D. and Guczi, L. (2004) A Review for in situ XAS Study of Co-Based Bimetallic Catalysts Relevant to CO Hydrogenation. Studies in Surf. Sci. and Catal., 147, 343350.

7 Lynch, J. (2002) Development of Structural Characterisation Tools for Catalysts. Oil \& Gas Science and Technology-Rev. IFP, 57, 281-305.

8 Bazin, D., Lynch, J., and Ramos-Fernandez, M. (2003) X-ray Absorption Spectroscopy and Anomalous Wide Angle X-Ray Scattering: Two Basic Tools in the Analysis of Heterogeneous Catalysts, Oil \& Gas Science and Technology Rev. IFP, 58, 667-683; see also references cited herein.

9 For more information about the CARAYSS (CAtalyse et RAYonnement Synchrotron à SOLEIL) network, please contact its responsible Edmond Payen (Edmond.Payen@univ-lille1.fr)

10 Briois, V., Belin, S., Villain, F., Bouamrane, F., Lucas, H., Lescouëzec, R., Julve, M., Verdaguer, M., Tokumoto, M.S., Santilli, C.V., Pulcinelli, S.H., Carrier, X., Krafft, J.M., Jubin, C. and Che, M. (2005) New Insights for Materials Science Characterisation Using Different Complementary Techniques Combined with X-ray Absorption Spectroscopy. Physica Scripta T115, 38-44.

11 Briois, V., Giorgetti, Ch., Baudelet, F., Flank, A.M., Tokumoto, M.S., Pulcinelli, S.H. and Santilli, C.V. (2004) Applications of $\mathrm{X}$-Ray Absorption Spectroscopy in Materials Science, in Spectroscopy of Emerging Materials, E.C. Faulques et al. (eds.) Kluwer Academic Publishers, Netherlands, 15-30.

12 Briois, V., Lützenkirchen-Hecht, D., Villain, F., Fonda, E., Belin, S., Griesebock, B. and Frahm, R. (2005) TimeResolved Tudy of the Oxidation of Ethanol by Cerium(IV) Using Combined Quick-XANES, UV-Vis, and Raman Spectroscopies. J. Phys. Chem. A, 109, 320-329.

13 Thomas, J.M., Greaves, G.N. and Catlow, C.R.A. (1995) Solid Catalysts Studied under Operating Conditions. NIM, B97, 1-10.

14 Clausen, B., Topsoe, H. and Frahm, R. (1998) Applications of Combined X-ray Diffraction and Absorption Techniques for in situ Catalyst Characterization. Adv. Catalysis, 42, 315344.

15 Matsuchita, T. and Phizackerley, R.P. (1981) A Fast X-Ray Absorption Spectrometer for Use with Synchrotron Radiation. Jpn. J. Appl. Phys., 20, 223.

16 Dartyge, E., Depautex, C., Dubuisson, J.M., Fontaine, A., Jucha, A., Leboucher, P. and Tourillon, G. (1986) X-Ray Absorption in Dispersive Mode: A New Spectrometer and Data Acquisition System For Fast Kinetics. Nucl. Inst. and Methods in Physics Research, A246, 452-460.

17 Tourillon, G. (1986) in Handbook of Conducting Polymers, (Ed.), T. Skotheim, Dekker-New-York, 1, 294.
18 Newton, M.A., Dent, A.J. and Evans, J. (2002) Bringing Time Resolution to EXAFS: Recent Developments and Application to Chemical Systems. Chem. Soc. Rev., 31, 2, 83-95.

19 Hagelstein, M., Fontaine, A. and Goulon, J. (1993) High Brillance Beamline for Time Resolved X-ray Absorption Spectroscopy at ESRF. Jpn. J. Appl. Phys., 32 Suppl. 32-2, 240-242.

20 Pascarelli, S. and Neisius, T. (1998) ESRF Experiment Report $n^{\circ} \mathrm{HE}-369$.

21 Petitet, J.P., Baudelet, F., Carlès, P. and Beauverger, M. (2003) Study of the Oxidation of Nickel in Sub- and Supercritical Aqueous Solutions by X-ray Absorption NearEdge Structure, Proceeding of the 6th ISASF meeting, Versailles, April 4-6.

22 Bazin, D., Guczi, L. and Lynch, J. (2000) Real Time in situ Xanes Approach to Characterize Electronic State of Nanometer Scale Entities. Recent Research Developments in Physical Chemistry, 4, Part II, 259-289.

23 Groust, J.F., Pommier, C., Stievano, L., Villain, F., Giorgetti, C., Baudelet, F. and Massiani, P. Monitoring of Real Time Evolution fo $\mathrm{Ni}^{2+}$ Environment in Faujasite upon Rehydration by dispersive-EXAFS. Catalysis Letters, submitted.

24 Bazin, D. et al. (2000) Real Time in situ XANES Approach to Characterise Electronic State of Nanometer Scale Entities. Recent developments in Physical Chemistry, 4, II, 259-289.

25 Shido, T. and Prins, R. (1998) Application of Synchrotron Radiation to in situ Characterization of Catalysts. Current Opinion in Solid State \& Materials Science, 3, 330.

26 Ersen, O., Pierron-Bohnes, V., Ulhaq-Bouillet, C., Pirri, C., Tuilier, M.H., Berling, D., Bertoncini, P., Gailhanou M. and Thiaudière, D. (2002) Epitaxy Stabilised $\mathrm{CaF}_{2}$-Type Ternary $\mathrm{Co}_{1-\mathrm{x}} \mathrm{Fe}_{\mathrm{x}} \mathrm{Si}_{2}$ silicides on $\mathrm{Si}(111)$ : DAFS ${ }^{2}$ and HRTEM Measurements. Applied Surface Science, 188, 146-150.

27 Hennet, L., Thiaudière, D., Landron, C., Berar, J.F., Saboungi, M.L., Matzen, G. and Price, D.L. (2003) Anomalous X-ray Scattering on Molten Levitated Samples. Nuclear Instruments and Methods B, 207, Issue 4, 447-452.

28 Vrel, D., Girodon-Boulandet, N., Paris, S., Mazue, J.F., Couqueberg, E., Gailhanou, M., Thiaudière, D., Gaffet, E. and Bernard, F. (2002) A New Experimental Setup for the Time-Resolved X-ray Diffraction Study of Self-Propagating High Temperature Synthesis. Rev. Sci. Instrum., 73, 422-428.

29 Goudeau, P., Renault, P.O., Villain, P., Coupeau, C., Pelosin, V., Boubeker, B., Badawi, K.F., Thiaudière, D. and Gailhanou, M. (2001) Characterization of Thin Film Elastic Properties Using X-ray Diffraction and Mechanical Methods: Application to Polycrystalline Stainless Steel. Thin Solid Films, 398-399, 496-500.

30 Panicaud, B., Renault, P.O., Grosseau-Poussard, J.L., Dinhut, J.F., Thiaudière, D. and Gailhanou, M. (2002) Measurement of Stress Phosphated-Iron Oxide Layers by In-situ Diffraction of Synchrotron Radiation. Materials Science Forum, 404/407, 809-816.

31 Martinez-Criado, G., Somogyi, A., Hermann, M., Eickhoff, M. and Stutzmann, M. (2004) Direct Observation of Mn Clusters in GaN by X-ray Scanning Microscopy. Japanese Journal of Applied Physics, 43, L695-697.

32 Hennet, L., Thiaudière, D., Landron, C., Melin, P., Price, D.L., Coutures, J.P., Berar, J.F. and Saboungi, M.L. (2003) Melting Behaviour of $\mathrm{Y}_{2} \mathrm{O}_{3}$. Appl. Phys. Lett., 90, 115502.

33 Landron, C., Hennet, L., Thiaudière, D., Price, D.L. and Greaves, G.N. (2003) Structure of Liquid Oxides at Very High Temperatures. Nuclear Instruments and Methods B, 199, 481-488. 
34 Mathiak, G., Egry, I., Hennet, L., Thiaudière, D., Pozdnyakova, I. and Price, D.L, Aerodynamic Levitation and Inductive Heating - A New Concept for Structural Investigations of Undercooled Melts. International Journal of Thermophysics, in press.

35 http://www.synchrotron-soleil.fr/francais/lignes/APS-DiffSurf.pdf.

36 Jensen, J.A., Rider, K.B., Salmeron, M. and Somorjai, G.A. (1998) High Pressure Adsorbate Structures Studied by Scanning Tunneling Microscopy: $\mathrm{CO}$ on $\mathrm{Pt}(111)$ in Equilibrium with the Gas Phase. Phys. Rev. Lett., 80, 1228-1231.

37 Rider, K.B., Hwang, K.S., Salmeron, M. and Somorjai, G.A. (2001) Structure and Dynamics of Dense Monolayers of NO Adsorbed on $\mathrm{Rh}(111)$ in Equilibrium with the Gas Phase in the Torr Pressure Range. Phys. Rev. Lett., 86, 4330-4333.

38 Hendriksen, B.L. and Frenken, J.W.M. (2002) CO Oxidation on $\mathrm{Pt}(110)$ : Scanning Tunneling Microscopy Inside a HighPressure Flow Reactor. Phys. Rev. Lett., 89, 046101-04604.

39 Peters, K.F., Walkers, C.J., Steadman, P.J., Robach, O., Isern, H. and Ferrer, S. (2001) Adsorption of Carbon Monoxide on $\mathrm{Ni}(110)$ Above Atmospheric Pressure Investigated with Surface X-Ray Diffraction. Phys. Rev. Lett., 86, 5325-5328.

40 Peters, K.F., Steadman, P.J., Isern, H., Alvarez, J. and Ferrer, S. (2000) Elevated-Pressure Chemical Reactivity of Carbon Monoxide over Au(111). Surf. Sci., 467, 10-22.

41 Quirós, C., Robach, O., Isérn, H., Ordejon, P. and Ferrer, S. (2003) Compressibility of CO Adsorbed on Ni(111) from $10^{-6}$ mbar to 1.2 bar Ambient CO Pressures Investigated with X-ray diffraction. Surf. Sci., 522, 161-166.

42 Ackermann, M., Robach, O., Walker, C., Quirós, C., Isérn, H. and Ferrer, S. (2004), Hydrogenation of Carbon Monoxide on $\mathrm{Ni}(111)$ Investigated with Surface X-ray Diffraction at Atmospheric Pressure. Surf. Sci., 557, 21-30.

43 Saint-Lager, M.C., Jugnet, Y., Dolle, P., Piccolo, L., Baudoing-Savois, R., Bertolini, J.C., Bailly, A., Robach, O., Walker, C. and Ferrer, S. Butadiene Selective Hydrogenation on $\mathrm{Pd}_{8} \mathrm{Ni}_{92}(110)(\mathrm{Nx} 1)$ : A Novel in situ X-ray Diffraction Study of Surfaces Under Reaction Conditions. Phys. Rev., submitted.

44 Revenant, C., Leroy, F., Lazzari, R., Renaud, G. and Henry, C.R. (2004) Quantitative Analysis of Grazing Incidence Small-Angle X-ray Scattering: $\mathrm{Pd} / \mathrm{MgO}(001)$ Growth. Phys. Rev. B 69, 035411-035426

45 See, for example, ARAGO 27, Nanomatériaux, OFTA, Paris (2001).

46 Gorigh, G., Haubold, H., Lyon, O. and Simon, J.P. (2003) Anomalous Small-Angle X-ray Scattering in Materials Science. J. Appl. Cryst., 36, 425-429.

47 Thomann, A.L., Rozenbaum, J.P., Brault, P., AndreazzaVignole, C. and Andreazza, P. (2000) Pd Nanoclusters Grown by Plasma Sputtering Deposition on Amorphous Substrates. Appl. Surf. Sci., 158, 172-183.

48 Andreazza, P., Andreazza-Vignolle, C., Rozenbaum, J.P., Thomann, A.L. and Brault, P. (2002) Nucleation and Initial Growth of Platinum Island by Plasma Sputter Deposition. Surface Coat. Tech., 151, 122-127.

49 Revenant, C., Leroy, F., Lazzari, R., Renaud, G. and Henry C.R. (2004) Quantitative Analysis of Grazing Incidence SmallAngle X-ray Scattering: $\mathrm{Pd} / \mathrm{MgO}(001)$ Growth. Phys. Rev. B69, 035411; Renaud, G. and Barbier, A. (1999) Grazing Incidence X-ray Scattering Study of the $\mathrm{Pd} / \mathrm{MgO}(001)$ Interface during its Formation. Surf. Sci., 433-435, 142-146.

50 Levine, J.R., Cohen, J.B., Chung, Y.W. and Georgopoulos, P. (1989) Grazing-Incidence Small-Angle X-ray Scattering:
New Tool for Studying Thin Film Growth. J. Appl. Crystallogr., 22, 528-532.

51 Babonneau, D., Naudon, A., Cabioc'h, T. and Lyon, O. (2000) Morphology of Encapsulated Iron Nanoparticles Obtained by Co-Sputtering and Implantation: a GISAXS study. J. Appl. Crystallogr., 33, 437-441.

52 Rauscher, M., Paniago, R., Metzger, H., Kovats, Z., Domke, J., Peisl, J., Pfannes, H.D., Schulze, J. and Eisele, I. (1999) Grazing Incidence Small Angle X-ray Scattering from FreeStanding Nanostructures. J. Appl. Phys., 86, 6763-6769.

53 Stangl, J., Holý, V., Roch, T., Daniel, A., Bauer, G., Zhu, J., Brunner, K. and Abstreiter, G. (2000) Grazing Incidence Small-Angle X-ray Scattering Study of Buried and FreeStanding SiGe Islands in a $\mathrm{SiGe} / \mathrm{Si}$ Superlattice. Phys. Rev. B62, 7229-7236.

54 Babonneau, D., Camelio, S., Girardeau, T., Guerin, P., Jaouen, M. and Lyon, O.J. (2003) Grazing Incidence SmallAngle X-ray Scattering of BN-Fe and BN-Ag Nanocomposite Films Obtained by Cosputtering and Multiayer Deposition Techniques. Appl. Cryst., 36, 430-434.

55 Drake, I.J., Liu, T.C.N., Gilles, M. Tyliszczak, T., David Kilcoyne, A.L., Shuh, D.K., Mathies, R.A. and Bell, A.T. (2004) An in situ Cell for Characterization of Solids by Soft X-ray Absorption. Rev. Sc. Inst., 75, 3242-3247.

56 Stöhr, J. (1992) NEXAFS Spectroscopy, Springer Verlag, Berlin.

57 Morar, J.F., Himpsel, F.J., Hollinger, G., London, J.L., Hughes, G. and Mc Feely, F.R. (1986) C1s Excitation Studies of Diamond (111). III. Unoccupied Surface States, Phys. Rev., B33, 1346.

58 Ade, H. and Uhrquart, S.G. (2000) NEXAFS Spectroscopy and Microscopy of Natural and Synthetic Polymers, in Chemical Application of Synchrotron Radiation, Sham, T.K. Ed., World Scientific Publishing, Singapore.

59 van der Laan, G., Thole, B.T., Sawatzky, G.A. and Verdaguer, M. (1988) Multiplet Structure in the $L_{23}$ X-rayAbsorption Spectra: A Fingerprint for High- and Low-Spin $\mathrm{Ni}^{2+}$ Compounds. Phys. Rev., B37, 6587.

60 Gokhale, S., Trischberger, P., Menzel, D., Widdra, W., Dröge, H., Steinrück, H.P., Birkenheuer, U., Gutdeutsch, U. and Rösch, N. (1998) Electronic Structure of Benzene Adsorbed on Single-Domain $\operatorname{Si}(001)-(2 \times 1)$ : A Combined Experimental and Theoretical Study. J. Chem. Phys., 108, 5554.

61 Rangan, S., Kulosky, S., Gallet, J.J., Bournel, F., Le Guen, K., Dufour, G., Rochet, F., Funke, R., Kneppe, M., Piaszenski, G., Köhler, U. and Sirotti, (F.) (2005) Dynamic and Kinetic Aspects of the Adsorption of Acrylonitrile on Si(001)-2×1. Phys. Rev., B71, 125320.

62 Bluhm, H., Ogletree, D.F., Fadley, C.S., Hussain, Z. and Salmeron, M. (2002) The Premelting of Ice Studied with Photoelectron Spectroscopy. J. Phys. Condens. Matter, 14, L227.

63 Vattuone, L., Savio, L., Rocca, M., Rumiz, L., Baraldi, A., Lizzit, S. and Comelli, G. (2002) Real-time XPS Investigation of the Impact-Energy Dependence of $\mathrm{C}_{2} \mathrm{H}_{4}$ Adsorption on Ag.100. Phys. Rev., B66, 085403.

64 Bauer, M., Lei, C., Read, K., Tobey, R., Gland, J., Murnane, M.M. and Kapteyn, H.C. (2001) Direct Observation of Surface Chemistry Using Ultrafast Soft-X-Ray Pulses. Phys. Rev. Lett., 87, 025501.

65 Schoenlein et al. (2000) Science, 287, 2237.

66 For a detailed review see (1997) J. Electron Spectrosc. Related Phenom., 84. 
67 Mundschau. M., Kordesch, M.E., Engel, W., Rausenberger, B., Zeitler E. and Bradshaw, A.M. (1990) Real-Time Observation of the Nucleation and Propagation of Reaction Front Surfaces using Photoemission Electron Microscopy. Surf. Sci., 227, 246.

68 Several Projects are presently under Development: PEEM3 (ALS- USA), SMART (BESSY II- Germany), Spectronanoscopy beamline (ELETTRA- Italy), Surface-Interface Microscopy Beamline (SLS-Switzerland).

69 Rotermund, H.H., Engel, J., Kordesch, M. and Ertl, G. (1990) Imaging of Spatio-temporal Pattern Evolution during Carbon Monoxide Oxidation on Platinum. Nature, 343, 355.

70 Imbihl, R. and Ertl, G. (1995) Oscillatory Kinetics in Heterogeneous Catalysis. Chem. Rev., 95, 697.

71 Gritsch, T., Coulman, D., Behm, R.J. and Ertl, G. (1989) Mechanism of the CO-Induced 1 x 2-->1 x 1 Structural Transformation of $\operatorname{Pt}(110)$. Phys. Rev. Lett., 63, 1086.

72 Kim, M., Bertram, M., Pollmann, M., von Oertzen, A., Mikhailov, A.S., Rotermund, H.H. and Ertl, G. (2001) Controlling Chemical Turbulence by Global Delayed Feedback: Pattern Formation in Catalytic CO Oxidation on Pt(110). Science, 292, 1357.

73 Von Oertzen, A., Mikhailov, A., Rotermund, H.H. and Ertl, G. (1998) Subsurface Oxygen in the CO Oxidation Reaction on Pt(110): Experiments and Modeling of Pattern Formation. J. Phys. Chem., B 102, 4966.

74 Rotermund, H.H., Lauterbach, J. and Haas, G. (1993) First Direct Observation of Subsurface Oxygen on Pt(100). Appl. Phys., A 57, 507.

75 Schaak, A. and Imbihl, R. (2000) J. Chem. Phys., 113, 9822; Schaak, A., Günther, S., Esch, F., Schütz, E., Hinz, M., Marsi, M., Kiskinova and Imbihl, R. (1999) Elementally Resolved Imaging of Dynamic Surface Processes: Chemical Waves in the System $\mathrm{Rh}(110) / \mathrm{NO}+\mathrm{H}_{2}$. Phys. Rev. Lett., 83, 1882.

76 Ertl, G. (1991) Oscillatory Kinetics and Spatio-Temporal Self-Organization in Reactions at Solid Surfaces. Science, 254, 1756.

77 Hilderbrand, M., Ipsen, M., Mikhailov, A.S. and Ertl, G. (2003) Localized Nonequilibrium Nanostructures in Surface Chemical reactions. New J. Phys., 5, 611.

78 Aballe, L., Barinov, A., Locatelli, A., Heun, S. and Kiskinova, M. (2004) Tunning Surface Reactivity via Electron Quantum Confinement. Phys. Rev. Lett., 93, 196103.

79 Locatelli, A., Sbraccia, C., Heun, S., Baroni, S. and Kiskinova, M. (2004) Energetically-Driven Reorganization of a Modified Catalytic Surface under Reaction Conditions. J. Am. Chem. Soc., in press

80 Locatelli, A., Heun, S. and Kiskinova M. (2004) Reorganisation of a $\mathrm{Au} / \mathrm{Rh}(110)$ Surface under Reaction Conditions. Elettra Highlights, Surface Science and Nanostructure, 79.

81 Stöhr, J., Wu, Y., Hermsmeier, B.D., Samant, M.G., Harp, G.R., Koranda, S., Dunham D. and Tonner, B.P. (1993) Element-Specific Magnetic Microscopy with Circularly Polarized X-rays. Science, 259, 658.

82 Nolting, F., Scholl, A., Stöhr, J., Seo, J.W., Fompeyrine, J., Siegwart, H., Locquet, J.P., Anders, S., Lüning, J.E., Fullerton, E., Toney, M.F., Scheinfein, M.R. and Padmore, H.A. (2000) Direct Observation of the Alignment of Ferromagnetic Spins by Antiferromagnetic Spins. Nature, 405, 767.

83 Neuber, M., Zharnikov, M., Walz, J. and Grunze, M. (1999) The Adsorption Geometry of Benzoic Acid on Ni(110). Surf. Rev. Lett., 6, 53.
84 Zharnikov, M. and Neuber, M. (2000) Characterization of Adsorbate Ensembles by X-ray Linear Dichroism Microscopy. Surf. Sci., 464, 8.

85 Sacchi, M., Hague, C. and Belkhou, R. (2002) APS for a High Flux and MicroFocus Beamline at SOLEIL. http://www.synchrotron-soleil.fr/francais/lignes/BL1.pdf

86 Rempfer, G.F. and Mauck, M.S. (1992) Correction of Chromatic Abberation with an Electron Mirror. Optik, 92, 3-8.

87 Dumas, P. and Williams, G.P. (2002) Surface Science and Microscopy Investigations Using Infrared Synchrotron Radiation, In Chemical Applications of Synchrotron radiation, vol. 12A in Advanced Series in Physical Chemistry; Sham, T.K., Ed.; World Scientific: Singapore, 12A, 356-387.

88 Hemley, R.J., Mao, H.K., Goncharov, A.F., Hanfland, M. and Victor, V.S. (1996) Synchrotron Infrared Spectroscopy to $0.15 \mathrm{eV}$ of $\mathrm{H}_{2}$ and $\mathrm{D}_{2}$ at Megabar Pressures. Phys. Rev. Lett., 76, 1667.

89 Carr, G.L., Hanfland, M. and Williams, G.P. (1995) The Mid-Infrared Beamline at the NSLS Port U2B. Rev. Sci. Instr., 66, 1643-1645.

90 Carr, G.L., Reffner, J.A. and Williams, G.P. (1995) Performance of an Infrared Microspectrometer at the NSLS. Rev. Sci. Instr., 66, 1490-1492.

91 Duncan, W.D. and Williams, G.P. (1983) Infrared Synchrotron radiation from Electron Storage-rings. Appl. Opt., 22, 2914.

92 Bosch, R.A. (1997) Edge Radiation as a Source for Infrared Beamline. Nucl. Instrum. Meth. in Phys. Research, A 386, 525 .

93 Matthis, Y.L., Roy, P., Tremblay, B., Nucara, A., Lupi, S., Calvani, P. and Gerschel, A. (1998) Magnetic Field Discontinuity as a New Brighter Source of Infrared Synchrotron radiation. Phys. Rev. Lett., 80, 1220.

94 Chubar, O. and Elleaume, P., www.esrf.fr/machine/support/ ids/Public/Codes/SRW/srwindex.html

95 Carr, G.L. (1999) High Resolution Microspectroscopy and Sub-Nanosecond Time Resolved Time Spectroscopy with the Synchrotron Infrared Source. Vibrational Spectroscopy, 19, 53-60.

96 Carr, G.L., Lobo, R., LaVeigne, J. and Reitze, D. (2000) Exploring the Dynamics of Superconductors by TimeResolved Far-Infrared Spectroscopy. Phys. Rev. Lett., 85, 3001-3004.

97 Dumas, P. and Miller, L. (2003) Biological and Biomedical Applications of Synchrotron Infrared Microspectroscopy. Journal of Biological Physics, 29, 201-218.

98 Dumas, P. and Miller, L. (2003) The Use of Synchrotron Infrared Microspectroscopy in Biological and Biomedical Investigations. Vibrational Spectroscopy, 32, 3-21.

99 Lamberti, C., Prestipino, C., Bordiga, S., Berlier, G., Spoto, G., Zecchina, A., Laloni, A., La Manna, F., D’Anca, F., Felici, R., D'Acapito, F. and Roy, P. (2003) Description of a Flexible Cell for in situ X-ray and Far-IR Characterization of the Surface of Powdered Materials. Nuclear Instruments and Methods in Physics Research, B 200, 196-201.

100 Bolis, V., Maggiorini, S., Meda, L., D’Acapito, F., Turnes Palomino, G., Bordiga, S. and Lamberti, C. (2000) X-ray Photoelectron Spectroscopy and X-ray Absorption near Edge Structure Study of Copper Sites Hosted at the Internal Surface of ZSM-5 Zeolite: A Comparison with Quantitative and Energetic Data on the $\mathrm{CO}$ and $\mathrm{NH}_{3}$ Adsorption. J. Chem. Phys., 113, 9248.

101 Otero Areán, C., Turnes Palomino, G., Zecchina, A., Spoto, G., Bordiga, S. and Roy, P. (1999) Cation-Carbon Stretching 
Vibration of Adducts Formed upon CO Adsorption on Alkaline Zeolites. Phys. Chem. Chem. Phys., 1, 4139.

102 Garrone, E., Bonelli, B., Lamberti, C., Civalleri, B., Rocchia, M., Roy, P. and Otero Areán (2002) Coupling of Framework Modes and Adsorbate Vibrations in $\mathrm{CO}_{2}$ on Alkali ZSM-5 Zeolites: Spectroscopic Studies in the Mid- and Far-IR and Ab-Initio Modelling. J. Chem. Phys., 117, 10274.

103 Dumas, P., Suhren, M., Hirschmugl, C.J., Chabal, Y.J. and Williams, G.P. (1997) Adsorption and Reactivity of NO on $\mathrm{Cu}(111)$ : a Synchrotron Infrared Reflection Adsorption Spectroscopic Study. Surf. Sci., 371200.

104 Mittleman, D.M., Jacobsen, R.H. and Nuss, M.C. (1996) T-ray Imaging. IEEE J. Sel. Top. Quantum Electron., 2, 679-692.
105 Keller, L.P., Hony, S., Bradley, J.P., Molster, F.J., Waters, L.B.F.M., Bouwman, J., de Koter, A., Brownlee, D.E., Flynn, G.J., Henning, T. and Mutschke, H. (2002) Identification of Iron Sulfide Grains around Protostars and in Protoplanetary Disks. Nature, 417, 148-150.

106 Miller, L.M., Smith, G.D. and Carr, G.L. (2003) Synchrotronbased Biological Microspectroscopy: From the Mid-Infrared through the Far-Infrared Regimes. J. of Biological Physics, 29219 . 